\title{
Posttraining Ablation of Adult-Generated Neurons Degrades Previously Acquired Memories
}

\author{
Maithe Arruda-Carvalho, ${ }^{1,3 \star}$ Masanori Sakaguchi, ${ }^{1,2,3 \star}$ Katherine G. Akers, ${ }^{1,2,3}$ Sheena A. Josselyn, ${ }^{1,2,3}$ \\ and Paul W. Frankland ${ }^{1,2,3}$ \\ ${ }^{1}$ Program in Neurosciences and Mental Health, The Hospital for Sick Children, Toronto, Canada M5G 1X8, 2Department of Physiology, University of \\ Toronto, Toronto, Canada M5S 1A8, and ' Institute of Medical Science, University of Toronto, Toronto, Canada M5S 1A8
}

\begin{abstract}
New neurons are continuously generated in the subgranular zone of the adult hippocampus and, once sufficiently mature, are thought to integrate into hippocampal memory circuits. However, whether they play an essential role in subsequent memory expression is not known. Previous studies have shown that suppression of adult neurogenesis often (but not always) impairs subsequent hippocampusdependent learning (i.e., produces anterograde effects). A major challenge for these studies is that these new neurons represent only a small subpopulation of all dentate granule cells, and so there is large potential for either partial or complete compensation by granule cells generated earlier on during development. A potentially more powerful approach to investigate this question would be to ablate adultgenerated neurons after they have already become part of a memory trace (i.e., retrograde effects). Here we developed a diphtheria toxin-based strategy in mice that allowed us to selectively ablate a population of predominantly mature, adult-generated neurons either before or after learning, without affecting ongoing neurogenesis. Removal of these neurons before learning did not prevent the formation of new contextual fear or water maze memories. In contrast, removal of an equivalent population after learning degraded existing contextual fear and water maze memories, without affecting nonhippocampal memory. Ablation of these adult-generated neurons even 1 month after learning produced equivalent memory degradation in the water maze. These retrograde effects suggest that adultgenerated neurons form a critical and enduring component of hippocampal memory traces.
\end{abstract}

\section{Introduction}

Division of progenitor cells in the subgranular zone leads to the continuous addition of new neurons to the adult hippocampus, a brain region that plays a central role in memory formation (Deng et al., 2010). These newly generated neurons initially migrate into the granule cell layer of the dentate gyrus (DG) and, over the course of several weeks, gradually establish functional afferent and efferent connections (Zhao et al., 2006; Toni et al., 2007, 2008). Previous studies have shown that, once sufficiently mature, adult-generated neurons are activated during memory formation and/or expression (Kee et al., 2007; Tashiro et al., 2007; Trouche et al., 2009; Stone et al., 2011), suggesting that they become integrated into hippocampal memory traces. However, these correlative studies do not establish whether these neurons

Received July 5, 2011; revised Aug. 16, 2011; accepted Aug. 31, 2011.

Author contributions: M.A.-C., M.S., S.A.J., and P.W.F. designed research; M.A.-C., M.S., and K.G.A. performed research; M.A.-C., M.S., and K.G.A. analyzed data; and S.A.J. and P.W.F. wrote the paper.

This work was supported by grants from the Canadian Institutes of Health Research to P.W.F. (MOP86762) and S.A.J. (MOP74650). M.A.-C., M.S., and K.G.A. were supported by fellowships from the Ontario Graduate Scholarship program (M.A.-C.), The Hospital for Sick Children (M.A.-C.), Japanese Society for the Promotion of Science (M.S.), and the Canadian Institutes of Health Research (K.G.A.). We thank R. Kageyama and I. Imayoshi for the nestin-Cre ${ }^{\text {ERT2 }}$ mice, A. Waisman for the iDTR mice, D. Lagace for technical advice, R. Aleixo for artwork, and C. Teixeira, A. Corvelo, and members of the Frankland/Josselyn laboratories for discussions and technical assistance.

M.A.-C. and M.S. contributed equally to this work.

The authors declare no competing financial interests.

Correspondence should be addressed to Paul W. Frankland at the above address. E-mail: paul. frankland@sickkids.ca.

DOI:10.1523/JNEUROSCI.3432-11.2011

Copyright $\odot 2011$ the authors $\quad 0270-6474 / 11 / 3115113-15 \$ 15.00 / 0$ represent an essential component of a hippocampal memory. A direct way to test this would be to examine the impact of removing only this population of neurons after memory formation on subsequent expression of that memory. Although transgenic, pharmacological, and irradiation-based approaches have previously been used to manipulate adult neurogenesis before memory formation (Shors et al., 2001; Saxe et al., 2006; Dupret et al., 2008; Imayoshi et al., 2008; Zhang et al., 2008; Clelland et al., 2009; Deng et al., 2009; Garthe et al., 2009; Kitamura et al., 2009), it has been technically challenging to manipulate adult-generated neurons after learning.

To address this question, we developed a "tag and ablate" transgenic strategy that allowed us to tag adult-generated neurons, allow them to mature, and ablate them either before or after training (see Fig. 1a). To ablate neurons, we used a diphtheria toxin (DT)-based system (Buch et al., 2005; Han et al., 2009). Apoptotic cell death is reliably induced after DT binds to the DT receptor (DTR). Since mice do not express functional DTRs, and are therefore normally insensitive to DT (Middlebrook and Dorland, 1977), we used transgenic mice that express simian DTRs in a Cre recombinase-inducible manner (iDTR mice) (Buch et al., 2005). To restrict DT-induced apoptosis to adult-generated neurons, we crossed iDTR mice with nestin-Cre ${ }^{\text {ERT2 }}$ mice, in which a tamoxifen (TAM)-inducible Cre recombinase is expressed under the control of a nestin promoter (Imayoshi et al., 2008). In adult offspring from this cross, TAM administration induces permanent expression of DTRs in neural progenitor cells and their progeny, and subsequent administration of DT ablates only this 
tagged population of adult-generated neurons. We found that selective ablation of these tagged, adult-generated neurons immediately (or up to 1 month) after training impaired memory expression using three distinct hippocampus-dependent tasks. Therefore, our data indicate that adult-generated neurons, if available at the time of learning, come to form an essential and enduring component of hippocampal memory traces.

\section{Materials and Methods}

\section{Cell culture}

To verify that murine-derived cells are insensitive to DT, we conducted cell viability assays using two cell lines, one from mice ( $3 \mathrm{~T} 3$ cells) and one from monkey (2-2 cells). Cells were seeded in six-well plates $\left(2 \times 10^{5}\right.$ cells per plate). Twenty-four hours later, DT $(0,0.01,0.1$, or $1 \mathrm{ng} / \mathrm{ml})$ was applied to fresh medium. Supernatant and trypsinized cells were collected $72 \mathrm{~h}$ later. Cell viability was assessed by exclusion of trypan blue (Sigma). Internal duplicates were run for each condition.

\section{Mice}

Nestin-Cre $e^{E R T 2}$ mice. Nestin-Cre ${ }^{\text {ERT2+ }}$ mice express TAM-inducible Cre recombinase under the control of a nestin promoter and have been described previously (Imayoshi et al., 2008). The line of nestin-Cre ${ }^{\text {ERT2 }}$ mice we used in our experiments corresponds to line 4 in the study by Imayoshi et al. (2008) and has the highest recombination efficiency in the subgranular zone of the hippocampus.

iDTR mice. iDTR mice have been described previously (Buch et al., 2005; Gropp et al., 2005). In iDTR ${ }^{+}$mice, the gene encoding DTR (simian Hbegf, heparin-binding epidermal growth factor-like growth factor) is under the control of the ubiquitous Rosa26 locus promoter, but expression of the DTR transgene is dependent on the Cre recombinasemediated removal of a transcriptional STOP cassette. It is important to note that neither high doses of DT in wild-type mice (Saito et al., 2001) nor expression of DTR alone (without DT) (Buch et al., 2005) produces behavioral abnormalities or cell death.

Rosa-LacZ mice. The Rosa-LacZ reporter mice have been described previously (Zambrowicz et al., 1997). Similar to iDTR mice, the gene encoding LacZ is under the control of the ubiquitous Rosa26 locus promoter, and expression of the LacZ transgene is dependent on the Cre recombinase-mediated removal of a transcriptional STOP cassette. We crossed this reporter line with nestin-Cre ${ }^{\text {ERT2 }}$ mice to initially characterize TAM-induced recombination because, unlike LacZ, which is expressed in the nucleus, DTRs are expressed as membrane proteins and are therefore difficult to quantify precisely. Importantly, we observed similar patterns of LacZ and DTR expression after TAM treatment when crossed with nestin-Cre ${ }^{\mathrm{ERT} 2}$ mice.

All lines were maintained on a C57BL/6 background (Taconic Farms). Genotypes were determined by PCR analysis of tail DNA samples as described previously (Zambrowicz et al., 1997; Buch et al., 2005; Imayoshi et al., 2008). Nestin-Cre ${ }^{\text {ERT2 }+}$ mice were bred with $\mathrm{iDTR}^{+/-}$or iDTR $^{+/+}$mice, resulting in nestin-Cre ${ }^{\mathrm{ERT} 2+} / \mathrm{iDTR}^{+}$, nestin-Cre ${ }^{\mathrm{ERT} 2+} /$ iDTR $^{-}$, nestin-Cre ERT2- $^{\text {iDTR }}{ }^{+}$, and nestin-Cre ERT2- $^{\text {iDTR }}{ }^{-}$offspring. An equivalent breeding strategy was used for the LacZ reporter line. Except in the case of wild-type mice, all of the transgenes were kept as heterozygote in the chromosome of each transgenic mouse to avoid possible complications of overexpressing Cre recombinase (Forni et al., 2006) or loss of the Rosa allele (Zambrowicz et al., 1997). In all ablation experiments, we compared double-transgenic mice (2xTg; nestin-Cre$\mathrm{ERT}^{+} / \mathrm{iDTR}^{+}$) with control, single-transgenic littermate mice (CTR; nestin-Cre ${ }^{\mathrm{ERT}^{+}+} / \mathrm{iDTR}^{-}$or nestin-Cre $\left.{ }^{\mathrm{ERT}^{-}-} / \mathrm{iDTR}^{+}\right)$. Both CTR and 2xTg mice were treated with TAM and, subsequently, DT (see below). Importantly, this design ensures that group effects cannot be attributed to nonspecific effects of TAM or DT. To characterize TAM-induced recombination, we compared nestin-Cre ${ }^{\mathrm{ERT} 2+} / \mathrm{Rosa}_{-} \mathrm{LaCZ}^{+}$versus Nestin$\mathrm{Cre}^{\mathrm{ERT} 2-} /$ Rosa-LacZ ${ }^{+}$mice.

Mice were bred in our colony at The Hospital for Sick Children and maintained on a $12 \mathrm{~h}$ light/dark cycle with ad libitum access to food and water. Before all behavioral experiments, mice were handled for $2 \mathrm{~min}$ twice per day for $5 \mathrm{~d}$. Male and female offspring were used in all experi- ments. All experiments were performed in the light cycle and conducted in accordance with The Hospital for Sick Children Animal Care and Use Committee.

\section{Drugs}

TAM treatment. TAM (Sigma) was dissolved in minimal ethanol and suspended in sunflower seed oil (Lagace et al., 2007). Mice received three rounds of TAM treatment. In each round, mice received daily injections $(180 \mathrm{mg} / \mathrm{kg}$, i.p.) for $5 \mathrm{~d}$, and each round was 4 weeks apart.

DT treatment. Preparation and delivery of DT was described previously (Han et al., 2009). DT (Sigma) was dissolved in PBS and readily crosses the blood-brain barrier (Wrobel et al., 1990). In the majority of experiments, mice received daily injections of DT ( $16 \mu \mathrm{g} / \mathrm{kg}$, i.p) for $7 \mathrm{~d}$. In two experiments (the visual discrimination and remote water maze experiments), mice received injections for $2 \mathrm{~d}$. We chose $2 \mathrm{~d}$ of DT treatment in these experiments because we observed significant forgetting after a week-long retention delay in preliminary visual discrimination experiments.

\section{Immunohistochemistry}

Mice were perfused transcardially with PBS $(0.1 \mathrm{M})$ and $4 \%$ paraformaldehyde (PFA). Brains were removed, fixed overnight in PFA, and transferred to $0.1 \mathrm{M}$ PBS. Coronal sections $(40 \mu \mathrm{m})$ were cut using a vibratome (VT1200S; Leica). The following primary antibodies were used: rabbit monoclonal anti-calbindin (D28K; 1:600; Cell Signaling Technology), mouse monoclonal anti-calretinin (1:1500; Swant), goat polyclonal anti-doublecortin (DCX; 1:4500; Santa Cruz Biotechnology), rabbit polyclonal anti-Egr1 (Zif268; 1:10000; Santa Cruz Biotechnology), rabbit polyclonal anti-ER $\alpha$ (1:1000; Santa Cruz Biotechnology), mouse monoclonal anti-glial fibrillary acidic protein (GFAP; 1:120,000; Cell Signaling Technology), rabbit polyclonal anti-Ibal (1:1200; Wako Chemicals), mouse monoclonal anti-NeuN (1:1000; Millipore), rabbit polyclonal anti-LacZ (1:6000; Invitrogen), mouse monoclonal antinestin (1:150; BD PharMingen), rabbit polyclonal anti-Ki67 (1:10,000; Abcam), and goat anti-human heparin binding-EGF (DTR; 1:150; R\&D Systems). All sections were treated with $1 \%$ hydrogen peroxidase. Sections were then incubated overnight with the primary antibody and then for $60 \mathrm{~min}$ at $20^{\circ} \mathrm{C}$ with HRP-conjugated or biotinylated secondary antibodies (1:750; Jackson Immunoresearch Laboratories). Signals were amplified and visualized using the Vectastain Elite ABC kit (Vector Laboratories), tyramide signal amplification, Alexa-Fluor conjugated streptavidin (Invitrogen), or DAB. Sections were mounted on slides with Permafluor antifade medium. For Ki67 staining, slides were counterstained with methyl green and mounted with Cytoseal 280 mounting medium (Thermo Fisher Scientific).

\section{Imaging and quantification}

All images were acquired using epifluorescent (either a Nikon Eclipse 80i or an Olympus BX61) or confocal (LSM 710; Zeiss) microscopes. To calculate cell number, cell density, or proportion of double-positive cells, we used one-fifth systematic section sampling fractions covering the entire anteroposterior extent of the DG. To calculate the proportion of double-labeled cells, confocal $1 \mu \mathrm{m} Z$-stack images were obtained using ZEN software (Zeiss) with a minimal interval of $15 \mu \mathrm{m}$ to prevent duplicate counts of the same cell. We quantified $\mathrm{Ki} 7^{+}$cells throughout the anteroposterior extent of the DG using a $10 \times$ objective on the Eclipse $80 \mathrm{i}$ epifluorescence microscope (Nikon). We estimated the total number of $\mathrm{LacZ}^{+}$cells after TAM treatment using the optical fractionator method on the BX61 epifluorescence microscope (Olympus) using a $60 \times, 1.45$ NA objective and a motorized XYZ stage attached to a computer with StereoInvestigator 9.1 (MBF Bioscience) (Chen et al., 2004). A random systematic sampling was used for these stereological analyses (section interval, one-fifth; grid size, $250 \times 250 \mu \mathrm{m} ; 2 \mathrm{D}$ counting frame, $90 \times 90$ $\mu \mathrm{m}$; fractionators, $30 \mu \mathrm{m}$ in thickness). Tissue thickness measured in each counting frame was used to estimate the total number of $\mathrm{LacZ}^{+}$cells in the entire DG. Conditions were optimized to obtain a Gundersen coefficient of error below 0.05 (Gundersen et al., 1999). We quantified $\mathrm{GFAP}^{+}$cells and $\mathrm{Iba}^{+}{ }^{+}$cells in the DG and CA1 throughout the entire anteroposterior extent of the hippocampus. Using StereoInvestigator software and the BX61 epifluorescence microscope (Olympus), we cre- 
ated separate contours for the DG and the CA1. All GFAP ${ }^{+}$and $\mathrm{Ibal}^{+}$ cells within the contours were counted using a $40 \times$ objective. Cell density was calculated by the total number of cells divided by the total area of the contours.

\section{General behavioral apparatus and procedures}

Context fear conditioning. In the fear conditioning experiments, three contexts were used. Context A (the training context) consisted of a stainless steel conditioning chamber $(31 \times 24 \times 21 \mathrm{~cm}$; MED Associates $)$, containing a stainless steel shock grid floor. Shock grid bars (diameter, $3.2 \mathrm{~mm}$ ) were spaced $7.9 \mathrm{~mm}$ apart. The grid floor was positioned over a stainless-steel drop pan, which was lightly cleaned with 70\% ethyl alcohol to provide a background odor. The front, top, and back of the chamber were made of clear acrylic, and the two sides were made of modular aluminum. For context B, a white plastic floor covered the shock grid bars, and a plastic, triangular insert was placed inside the same conditioning chamber used for context A. One of the walls of this insert had a black/white-striped pattern. The other two walls were white. Context B was cleaned with water. As contexts A and B were located in the same windowless room and used common apparatus, they shared some overlapping features. In contrast, context C $(37 \times 16 \times 27 \mathrm{~cm})$ was located in a different room and contained features that were essentially distinct from context A or B. It was made of opaque acrylic walls, with bedding covering the floor. In contexts $\mathrm{A}$ and $\mathrm{B}$, mouse freezing behavior was monitored via overhead cameras. Freezing was assessed using an automated scoring system (Actimetrics), which digitized the video signal at 4 $\mathrm{Hz}$ and compared movement frame by frame to determine the amount of freezing. Freezing in context $\mathrm{C}$ was scored manually.

During training, mice were placed in context A. After 2 min, mice were presented with a $30 \mathrm{~s}$ tone $(2800 \mathrm{~Hz}, 85 \mathrm{~dB})$ that coterminated with a $2 \mathrm{~s}$ footshock $(0.5 \mathrm{~mA})$. Mice remained in the context for an additional $30 \mathrm{~s}$ before being returned to their home cage. Responsivity to the shock during training was estimated by comparing mouse velocity immediately preceding versus during shock presentation using the following formula: $\left(\right.$ velocity $_{\text {shock }}-$ velocity $\left._{\text {pre-shock }}\right) /\left(\right.$ velocity $_{\text {shock }}+$ velocity $\left._{\text {pre-shock }}\right)$.

Eight days after training, freezing was assessed in 5 min tests in contexts $\mathrm{A}$ and $\mathrm{B}(\sim 4 \mathrm{~h}$ intertest interval). In context $\mathrm{B}$, the tone was presented after a 2 min delay. Three hours later, freezing was assessed in a 2 min test in context C. Discrimination of contexts A and B was computed by comparing freezing in contexts $\mathrm{A}$ and $\mathrm{B}$ during the first 2 min of testing (i.e., before the tone was presented). As in previous studies, we used the following discrimination index (Corvelo and Eyras, 2008; Wang et al., 2009): (freezing ${ }_{c x t ~ A}-$ freezing $\left._{c x t ~ B}\right) / \max \left(\right.$ freezing $_{c x t ~ A}$, freezing cxt B $_{\text {B }}$ ). Discrimination scores ranged from -1 to +1 , with positive scores reflecting greater levels of freezing in context A compared with context B. This measure changes at the same rate regardless of the relative difference in freezing levels in contexts A and B, and therefore it is more sensitive in detecting small differences in relative freezing levels than other commonly used discrimination indices [e.g., (freezing ${ }_{c x t ~ A}-$ freezing $_{c x t ~ B}$ )/ (freezing cxt A + freezing $_{\text {cxt B }}$ )] (McHugh et al., 2007) that change slowly when differences are small and more rapidly when differences are large (Corvelo and Eyras, 2008). Importantly, we found no difference between statistical analyses based on our discrimination index compared with other commonly used discrimination indices.

Water maze (hidden platform version). The apparatus and behavioral procedures have been described previously (Teixeira et al., 2006; Kee et al., 2007). Behavioral testing was conducted in a circular water maze tank (120 cm in diameter, $50 \mathrm{~cm}$ deep), located in a dimly lit room. The pool was filled to a depth of $40 \mathrm{~cm}$ with water made opaque by adding white, nontoxic paint. Water temperature was maintained at $28 \pm 1^{\circ} \mathrm{C}$ by a heating pad located beneath the pool. A circular escape platform $(10 \mathrm{~cm}$ diameter) was submerged $0.5 \mathrm{~cm}$ below the water surface, in a fixed position in one of the quadrants. The pool was surrounded by curtains at least $1 \mathrm{~m}$ from the perimeter of the pool. The curtains were white and had distinct cues painted on them.

Water maze training took place over $5 \mathrm{~d}$. On each day, mice received three training trials (intertrial interval, $\sim 15 \mathrm{~s}$ ). For each trial, mice were released into the pool, facing the wall, at one of four pseudorandomly varied start locations. The trial was complete once the mouse found the platform or $60 \mathrm{~s}$ had elapsed. If the mouse failed to find the platform on a given trial, the experimenter guided the mouse onto the platform. After the completion of training, spatial memory was assessed in a $60 \mathrm{~s}$ probe test with the platform removed from the pool. Behavioral data from training and the probe tests were acquired and analyzed using an automated tracking system (Actimetrics). Using this software, we recorded a number of parameters during training, including escape latency and swim speed. In probe tests, we measured the amount of time mice searched the target zone $(23.6 \mathrm{~cm}$ in radius, centered on the location of the platform during training) versus the average of three other equivalent zones in other areas of the pool (Moser et al., 1993). Each zone represents $15 \%$ of the total pool surface.

Water maze (visual discrimination version). For the visual discrimination task, we modified the water maze apparatus described above. The pool contained two visual cues. These cues were cylindrical $(4 \mathrm{~cm}$ in diameter, $4 \mathrm{~cm}$ in height), with either a vertical or horizontal black/ white-striped pattern. One of these cues (counterbalanced across mice) was always positioned above the submerged escape platform $(10 \mathrm{~cm}$ in diameter, $0.5 \mathrm{~cm}$ below the surface of the water). A transparent plastic cylindrical bar ( $1 \mathrm{~cm}$ in diameter, $13 \mathrm{~cm}$ in height) connected the cue to the platform. The other nonreinforced cue was also positioned $13 \mathrm{~cm}$ above the surface of the water. For the nonreinforced cue, an identical transparent plastic cylindrical bar connected the cue to base of the pool. Nonpatterned white curtains replaced the curtains containing distal cues to minimize reliance on spatial strategies.

Visual discrimination training took place over $5 \mathrm{~d}$. Across training trials, the locations of the reinforced and nonreinforced cues were varied pseudorandomly. On each day mice, received six training trials (intertrial interval, $\sim 10 \mathrm{~min}$ ). On each trial, mice were released into the pool, facing the wall, at one of four pseudorandomly varied start locations. The trial was complete once the mouse found the escape platform or $60 \mathrm{~s}$ had elapsed. If the mouse failed to find the platform on a given trial, the experimenter guided the mouse onto the platform. Three days after the completion of training, discrimination memory was assessed in a $30 \mathrm{~s}$ probe test with both cues present, but with the platform removed from the pool. As before, behavioral data from training and the probe tests were acquired and analyzed using an automated tracking system. During the probe test, searching was highly focused around the two cues. Accordingly, we compared time spent in two zones ( $15 \mathrm{~cm}$ in radius) centered on the cue locations. Additionally, heat maps representing averaged group data were generated using Matlab (MathWorks). In the heat map, the average time(s) mice spent in a $6 \times 6 \mathrm{~cm}$ area of the pool was normalized for $n=10$ mice per group. Behavioral procedures were adapted from previous studies which established that posttraining lesions of the hippocampus disrupt visual discrimination memory (Sutherland et al., 2001; Epp et al., 2008).

\section{Specific experimental protocols}

Characterization of TAM-induced recombination. Nestin-Cre ${ }^{\mathrm{ERT} 2+}$ / Rosa-LacZ ${ }^{+}$or nestin-Cre ${ }^{\text {ERT2- }} /$ Rosa-LacZ ${ }^{+}$mice were treated with TAM. Seven weeks after the completion of TAM treatment, the number, distribution, and cellular phenotype of recombined $\mathrm{LacZ}^{+}$cells was quantified using immunohistochemical methods.

Characterization of TAM-induced recombination and ablation in $2 x \mathrm{Tg}$ mice. 2xTg mice were treated with TAM. Seven weeks after the completion of TAM treatment, mice received daily injections of PBS or DT for $7 \mathrm{~d}$. Twenty-four hours after the final DT injection, mice were perfused, and DTR, nestin, calretinin, and DCX expression were quantified immunohistochemically.

Characterization of basal proliferation rates in $2 x T g$ mice. To evaluate whether our tagging impacted ongoing proliferation in the adult hippocampus, we examined expression of Ki67 in CTR and 2xTg mice 7 weeks after the completion of TAM treatment. Ki67 is a cell-cycle-related nuclear protein, expressed by proliferating cells in all phases of the active cell cycle (Kee et al., 2002).

Contextual fear: posttraining ablation. CTR and 2xTg mice were treated with TAM. Seven weeks after the completion of TAM treatment, mice were trained in context A. Beginning $1 \mathrm{~d}$ later, mice received daily injec- 
tions of DT for $7 \mathrm{~d}$. One week after training, freezing was assessed in contexts $\mathrm{A}$ and $\mathrm{B}$ and then in context $\mathrm{C}$ in a subset of mice.

Contextual fear: pretraining ablation. CTR and $2 x T g$ mice were treated with TAM. Seven weeks after the completion of TAM treatment, mice were trained in context A. One week after training, freezing was assessed in contexts $\mathrm{A}$ and B and later in context C. In this experiment, mice received daily injections of DT for $7 \mathrm{~d}$ during the week preceding training.

Conditioned taste aversion: posttraining ablation. To evaluate whether posttraining DTinduced ablation impairs subsequent expression of a conditioned taste aversion memory, we trained CTR and 2xTg mice 7 weeks after the completion of TAM treatment, using previously described methods (Ding et al., 2008). During training, mice had access to a single bottle containing saccharin $(0.2 \%)$ for $30 \mathrm{~min}$. Forty minutes later, mice were treated with $\mathrm{LiCl}(0.15 \mathrm{M}$, i.p., $2 \%$ body weight). Beginning the next day, mice received daily injections of DT for $7 \mathrm{~d}$. One day later, conditioned taste aversion was assessed in a choice test in which mice had access to bottles containing either water or saccharin. An aversion index was calculated as saccharin consumed/total fluid consumed. An additional group of mice were treated identically except that they received an injection of saline (instead of $\mathrm{LiCl}$ ) during training.

Water maze, hidden platform version: posttraining ablation, recent group. CTR and 2xTg mice were treated with TAM. Seven weeks after the completion of TAM treatment, mice were trained in the hidden platform version of water maze for $5 \mathrm{~d}$. Beginning $1 \mathrm{~d}$ after the completion of water maze training, mice received daily injections of DT for $7 \mathrm{~d}$. One day later, spatial memory was assessed in a probe test. Additional groups of CTR and 2xTg mice were treated identically, except that they received PBS rather than DT during the $7 \mathrm{~d}$ before the probe test.

Water maze, hidden platform version: pretraining ablation. CTR and 2xTg mice were treated with TAM. Seven weeks after the completion of TAM treatment, mice were trained in the hidden platform version of the water maze for $5 \mathrm{~d}$, and spatial memory was tested in a probe test 1 week later. In this experiment, mice received daily injections of DT for $7 \mathrm{~d}$ during the week preceding training.

Water maze, hidden platform version: posttraining ablation, remote group. CTR and 2xTg mice were treated with TAM. Seven weeks after the completion of TAM treatment, mice were trained in the hidden platform version of water maze for $5 \mathrm{~d}$. Mice were treated identically to above except that $35 \mathrm{~d}$ after the completion of water maze training, mice received daily injections of DT for $2 \mathrm{~d}$. One day later, spatial memory was assessed in a probe test.

Water maze visual discrimination version: posttraining lesion. One day after training in the visual discrimination task, wild-type mice received sham lesions or NMDA lesions of the entire hippocampus as described previously (Wang et al., 2009). Two days later, discrimination was assessed in a probe test. Mice were perfused after the probe test. Brains were removed, fixed overnight in PFA, and transferred to 30\% sucrose. Coronal sections $(50 \mu \mathrm{m})$ were cut using a cryostat. Sections were mounted on gelatin-coated slides, stained with neutral red, and coverslipped with Cytoseal. Using StereoInvestigator software, the entire hippocampus and the area of the hippocampus sustaining damage were outlined separately for every fourth section. The proportion of total hippocampal tissue damaged was $66.2 \pm 7.3 \%$.

Water maze visual discrimination version: posttraining ablation. CTR and 2xTg mice were treated with TAM. Seven weeks after the completion of TAM treatment, mice were trained in the visual discrimination task. Beginning $1 \mathrm{~d}$ after the completion of training, mice received daily injec- tions of DT for $2 \mathrm{~d}$. One day later, discrimination was assessed in a probe test.

General behavioral characterization after DT-induced ablation. CTR and $2 x T g$ mice were treated with TAM. Seven weeks after the completion of TAM treatment, mice received daily DT injections for $7 \mathrm{~d}$, and behavior was evaluated in a battery of tests. All mice were given the following tests in the same order (open field, visual discrimination, beam walking, hanging grip, sticky dot/adhesive removal, forced swim).

For open-field testing, mice were placed in the center of a squareshaped arena $(45 \times 45 \times 20 \mathrm{~cm}$ height $)$ and allowed to explore for 20 min. The open-field apparatus was constructed of Plexiglas and was dimly lit from above. Mouse location was tracked by a camera located above the open field, and total distance traveled and time spent in three different zones (outer, middle, inner) was measured (Limelight2; Actimetrics). Total distance traveled was used as a measure of spontaneous motor activity, and distribution of activity in different regions of the arena was used as a measure of anxiety-related behavior (Archer, 1973).

To evaluate vision, we trained mice in the visual discrimination water maze task across 3 consecutive days (six trials per day). The latency to reach the platform and swim speed were recorded.

To assess sensorimotor control and locomotor activity, we used the beam walking task (Chen et al., 2004). Mice were placed on a beam (70 $\mathrm{cm}$ long, $2 \mathrm{~cm}$ wide, elevated $30 \mathrm{~cm}$ above floor) for $60 \mathrm{~s}$, and paw slips (forelimb and hindlimb) were recorded. Each mouse received three consecutive trials, and paw slips were calculated per distance traveled.

To evaluate muscle strength, the hanging grip test was used (Chen et al., 2004). In this test, mice were allowed to hang vertically from a metal wire using their forepaws. The latency to fall was measured. Importantly, mouse weights did not differ between genotypes.

To assess somatosensory function, we used the sticky dot or adhesive removal task (Schallert et al., 2000). Briefly, a small piece of tape was placed on the plantar surface of the mouse's forepaw. Time taken for mice to sense (i.e., shaking its paw or bringing its paw to its mouth) and remove the adhesive tape were recorded. Each mouse was tested three times, and data were averaged. Each test lasted a maximum of 3 min.

To assess depressive-like behaviors, we used the forced swim test (Porsolt, 1979). Mice were placed in a cylinder (radius, $6.5 \mathrm{~cm}$; height, $20 \mathrm{~cm}$ ) for $6 \mathrm{~min}$. The cylinder was filled to a depth of $12 \mathrm{~cm}$ with $25 \pm 1^{\circ} \mathrm{C}$ water. The time spent motionless was recorded for each mouse. 

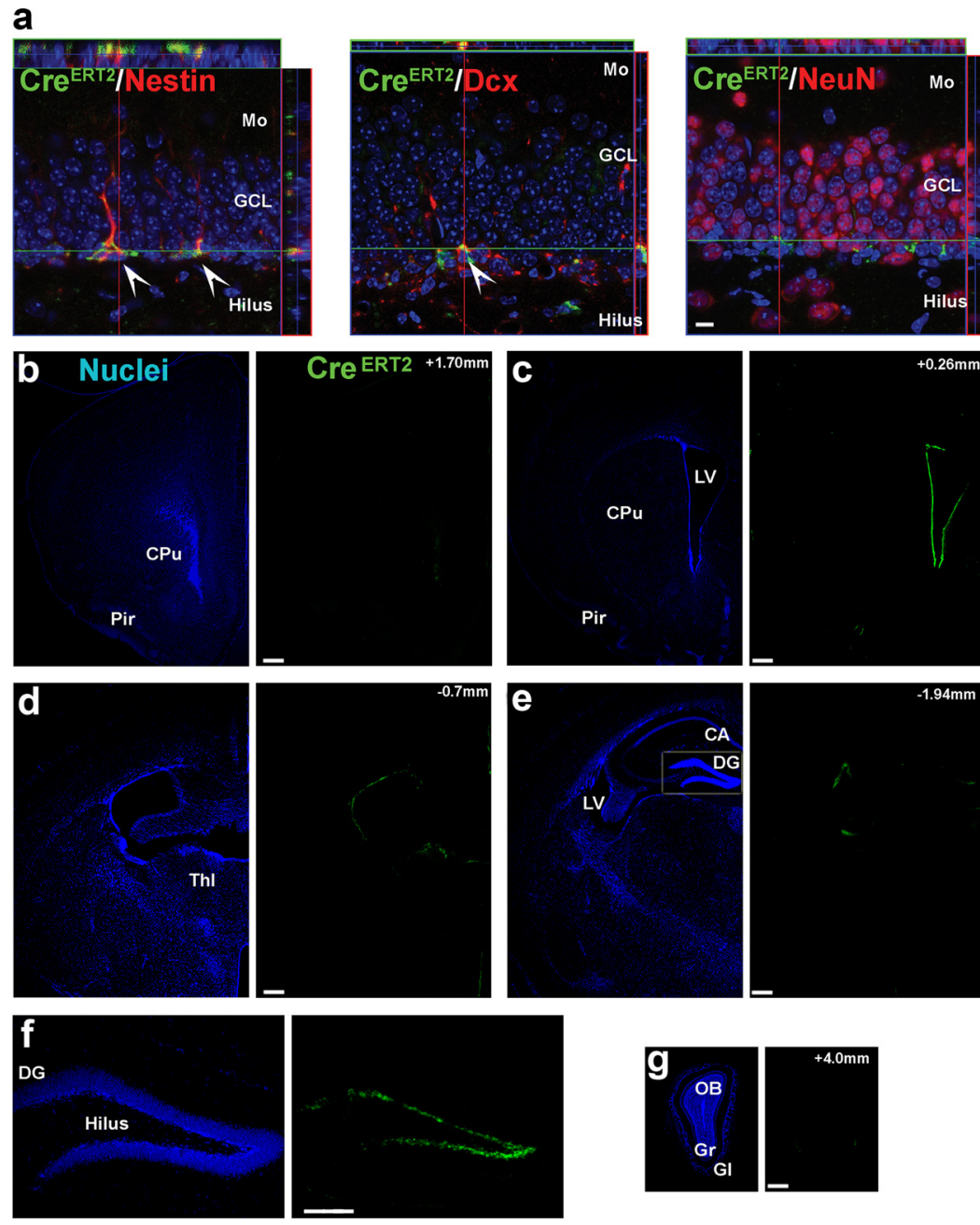

Figure 2. Cre ${ }^{\text {ERT2 }}$ expression is restricted to progenitor cells and limited to adult neurogenic regions. $\boldsymbol{a}$, In nestin-Cre ${ }^{\text {ERT2 }+}$ mice, $C r e^{\text {ERT2 }}$ protein expression (green) was found in nestin ${ }^{+}$and DCX ${ }^{+}$cells (red) but not mature neurons (NeuN; red) in the DG (scale bar, $10 \mu \mathrm{m}) . \boldsymbol{b}-\boldsymbol{g}$, In these mice, Cre ${ }^{\text {ERT2 }}$ protein expression was limited to the subgranular zone of the DG and the subventricular zone of the lateral ventricle (LV) (millimeters relative to bregma; scale bars, $250 \mu \mathrm{m}$ ). Mo, Molecular layer; $\mathrm{GCL}$, granule cell layer; $\mathrm{CPu}$, caudate-putamen; Pir, piriform cortex; Thl, thalamus; OB, olfactory bulb; Gr, granular layer; Gl, glomerular layer; CA, cornu ammonis.

\section{Table 1. Cell maturity markers}

\begin{tabular}{llll}
\hline & Nestin & DCX & NeuN \\
\hline $\begin{array}{l}\text { Percentage of Cre }{ }^{\text {ERT2 }+} \text { cells } \\
\text { expressing marker ( } \pm \text { SEM) }\end{array}$ & $97 \pm 0.94$ & $85 \pm 2.3$ & $0.72 \pm 0.26$ \\
\begin{tabular}{l} 
Cells analyzed \\
\hline
\end{tabular} & 490 & 460 & 474 \\
\hline
\end{tabular}

\section{Data analysis}

Data were analyzed using ANOVAs followed by $t$ tests. Because both male and female mice were used, sex was initially included as a factor in the ANOVAs. Consistent with previous studies (Jonasson, 2005), we found that males performed better than females in one of the water maze experiments (hidden platform version, posttraining ablation, recent group). However, we found no further effects of sex and no significant interactions between sex and genotype; therefore, this factor was dropped from analysis.

\section{Results}

\section{Murine cells are insensitive to DT}

We verified that murine cells are insensitive to DT using two cell lines, one derived from mice (3T3 cells) and the other
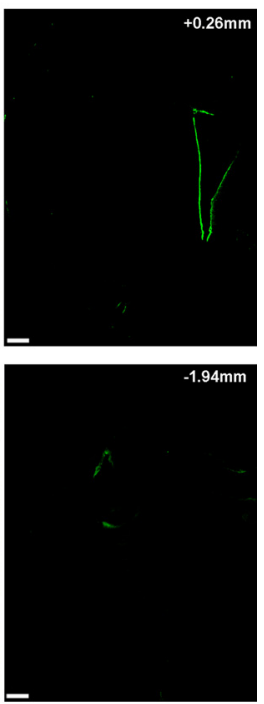

from monkey (2-2 cells). As expected, DT dose-dependently reduced the number and viability of $2-2$, but not $3 \mathrm{~T} 3$, cells (Fig. 1b,c) (Middlebrook and Dorland, 1977).

\section{Characterization of tag and ablate mice} Tagging new neurons

We first characterized TAM-induced recombination (tagging) in nestin-Cre ${ }^{\text {ERT2 }}$ mice by crossing them with rosa-LacZ reporter mice. In these reporter mice, Cremediated excision of a STOP cassette induces LacZ expression under the control of the Rosa26 promoter (the same promoter as in the iDTR mice). Consistent with previous results, at 4 weeks of age, $\mathrm{Cre}{ }^{\mathrm{ERT} 2}$ protein expression in nestin$\mathrm{Cre}^{\mathrm{ERT} 2+}$ mice was robust, restricted to progenitor cells (Fig. 2a, Table 1), and limited to adult neurogenic regions including the subgranular zone (Fig. $2 b-g$ ) (Imayoshi et al., 2008). As expected, TAM induced recombination $\left(\mathrm{LacZ}^{+}\right.$cell) in nestin-Cre ${ }^{\mathrm{ERT} 2+} / \mathrm{Rosa}^{-\mathrm{LacZ}^{+}}$reporter mice, and no recombination was observed in nestin-Cre ${ }^{\text {ERT2- }} /$ Rosa-LacZ ${ }^{+}$littermate controls (Fig. 3a). We next examined tagged cells 7 weeks after TAM administration was complete. As observed previously (Imayoshi et al., 2008), TAMinduced recombination in the dividing progenitor population was highly efficient, with $86.2 \pm 2.7 \%$ (mean \pm SEM) of $\mathrm{Ki}^{+} 7^{+}$cells and $77.7 \pm 7.8 \%$ of nestin ${ }^{+}$ cells in the DG expressing LacZ. Furthermore, $\mathrm{LacZ}^{+}$cells were uniformly distributed throughout the anteroposterior extent of the DG (Fig. 3b), suggesting no intraregional differences in TAMinduced recombination efficiency. Using stereological methods, we estimated there were 31,709 $\pm 2984 \mathrm{LacZ}^{+}$cells and 496,266 $\pm 46,556 \mathrm{NeuN}^{+}$ cells in the DG. Therefore, our tagged population of cells represents $\sim 6 \%$ of the entire population of DG neurons (i.e., 31,709 of $496,266)$.

To evaluate the phenotype of tagged cells, we next stained for proteins expressed at different stages of cell differentiation (Kempermann et al., 2004) (Fig. 3c). Ninety-four percent of tagged $\left(\mathrm{LacZ}^{+}\right)$cells were also positive for markers of mature neurons $(\mathrm{NeuN}$, calbindin) with far fewer $(<5 \%)$ that were positive for progenitor cell or immature neuronal markers (nestin, doublecortin, calretinin) (Fig. 3d, Table 2). Therefore, this predominantly mature population of tagged neurons corresponds to the population of adult-generated neurons that are activated during the formation and/or expression of hippocampus-dependent memories (Kee et al., 2007; Stone et al., 2011). Consistent with this, at this time point $\mathrm{LacZ}^{+}$cells expressed activity-dependent genes such as zif268 after training (Fig. $3 d$ ). Importantly, basal levels of proliferation in the hippocampus were unaltered by tagging (unpaired $t$ test, $p>$ 0.05) (Fig. 3e). 
a
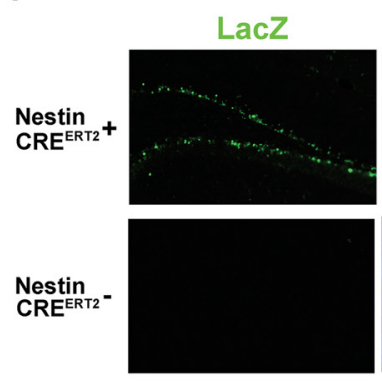

b

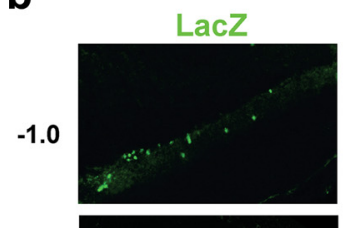

$-1.7$

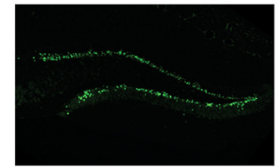

$-2.6$

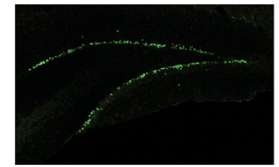

$-3.4$

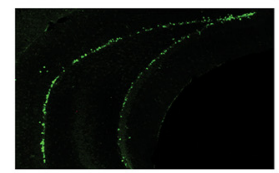

Nuclei
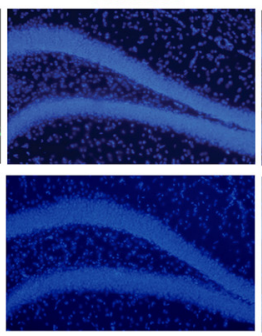

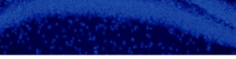

Nuclei
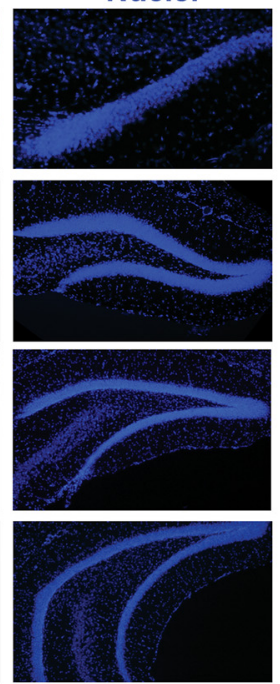
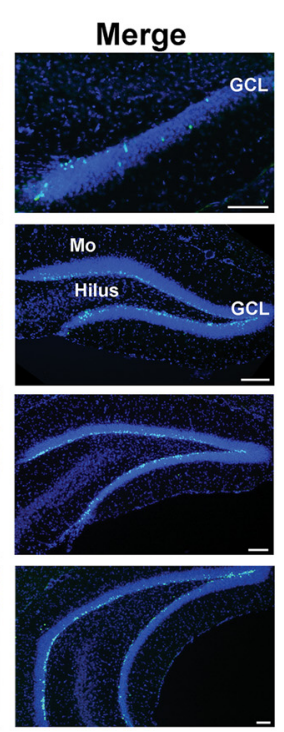

C

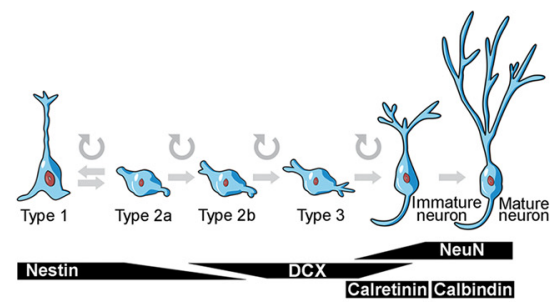

d
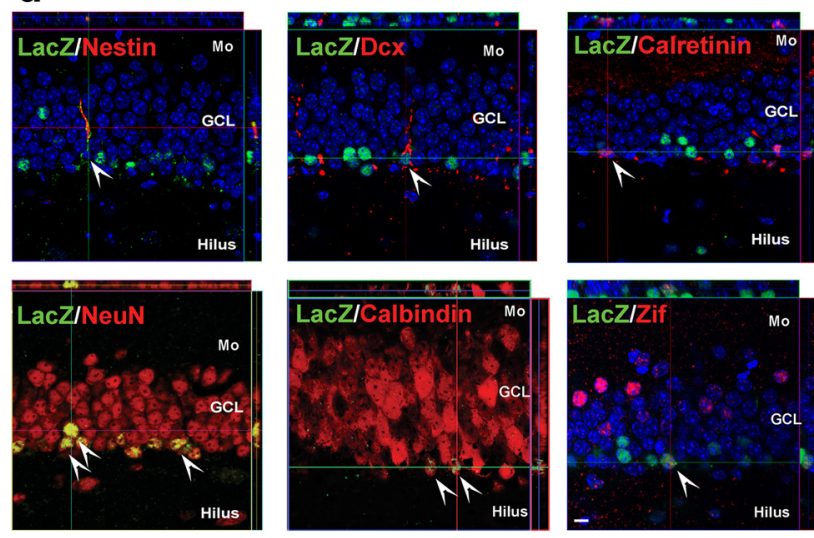

e

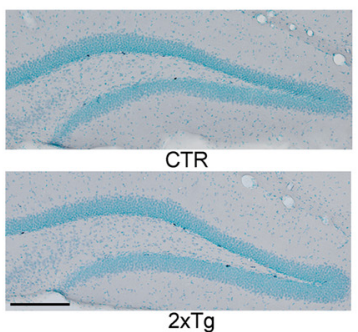

Figure 3. Tagging new neurons. $\boldsymbol{a}$, TAM-induced recombination occurs only in nestin-Cre ${ }^{\mathrm{ERT} 2+}$ mice (scale bar, $\left.50 \mu \mathrm{m}\right) \cdot \boldsymbol{b}$, Recombination occurred throughout the anteroposterior extent of the DG (millimeter relative to bregma; scale bars, $150 \mu \mathrm{m}$ ). c, Schematic showing markers associated with different developmental stages of adult hippocampal neurogenesis. $\boldsymbol{d}$, Seven weeks after the completion of TAM treatment, most LacZ ${ }^{+}$cells (green) costained for mature neuronal markers (NeuN, calbindin; red), with far less staining for progenitor cell or immature neuronal markers (nestin, $D C X$, calretinin; red). LacZ ${ }^{+}$cells additionally expressed activity-dependent gene zif268 (red) after behavioral testing. , Seven weeks after the completion of TAM treatment, Ki67 expression levels were similar in control (CTR; $n=11)$ and $2 x \operatorname{Tg}(n=7)$ mice, indicating that DTR expression has no effect on ongoing proliferative activity in the adult hippocampus (scale bar, $250 \mu \mathrm{m})$. Mo, Molecular layer; GCL, granule cell layer.

Table 2. Cell types

\begin{tabular}{llllll}
\hline & Type 1, 2a, 2b & Type 2b, 3, immature neuron & Immature neuron & Immature to mature neuron & Postmitotic mature neuron \\
\hline Cell maturity marker & Nestin & DCX & Calretinin & NeuN & Calbindin \\
Percentage of LacZ ${ }^{+}$cells expressing marker ( \pm SEM) & $3.1 \pm 1.1$ & $5.1 \pm 1.8$ & $0.72 \pm 0.46$ & $94 \pm 1.4$ & $94 \pm 2.1$ \\
Cells analyzed & 455 & 513 & 457 & 374 & 461 \\
\hline
\end{tabular}

\section{Ablating tagged neurons}

To ablate these tagged neurons, we crossed nestin-Cre ${ }^{\text {ERT2 }}$ mice with iDTR mice, in which Cre-mediated excision of a STOP cassette renders cells sensitive to DT (Buch et al., 2005). In TAMtreated nestin-Cre ${ }^{\mathrm{ERT} 2+} / \mathrm{iDTR}^{+}(2 \mathrm{xTg})$ mice, DTR-expressing cells were localized to the subgranular zone and innermost layer of the DG (consistent with the pattern of LacZ expression in the reporter mice above) (Fig. 4a). Subsequent systemic injection of DT (but not PBS) virtually abolished these DTR-expressing cells (100\% reduction; unpaired $t$ test: $t_{(8)}=1.93, p<0.05$ ) (Fig. $4 a$ ), indicating that DT treatment efficiently ablated the tagged neurons (Buch et al., 2005; Han et al., 2009). In the same mice, we additionally quantified numbers of progenitor cells and immature neurons in the DG after DT versus PBS treatment. We found that DT treatment greatly reduced overall numbers of doublecor$\operatorname{tin}^{+}$(Fig. $\left.4 b\right)$, nestin $^{+}\left(\sim 94 \%\right.$ reduction; unpaired $t$ test: $t_{(7)}=$
4.16, $p<0.01$ ) (Fig. $4 c)$, and calretinin ${ }^{+}(\sim 86 \%$ reduction; unpaired $t$ test: $t_{(6)}=2.03, p<0.05$ ) (Fig. $4 d$ ) cells in the DG of $2 \mathrm{xTg}$ mice. Whereas this subpopulation represents only a small proportion of all tagged cells $\left(\sim 94 \%\right.$ are $\mathrm{NeuN}^{+}$or calbindin $\left.{ }^{+}\right)$, nonetheless these data are consistent with the reduction in DTRexpressing cells and suggests that DT-induced ablation is highly efficient.

After DT treatment, there were similar numbers of astrocytes (unpaired $t$ tests, $p>0.05$ ) but increased microglia in the hippocampus (Fig. 5). The increase in microglia was limited to the DG (unpaired $t$ test: $t_{(7)}=3.46, p<0.01$ ) and not observed in CA1 (unpaired $t$ test, $p>0.05$ ); therefore, it likely reflects localized phagocytosis after DT-induced apoptotic cell death. Furthermore, TAM and DT treatment produced no changes in mouse weight (unpaired $t$ tests, $p>0.05$ ) (Fig. 6a) or in a range of tests assessing emotion, vision, motor, or somatosensory func- 
a

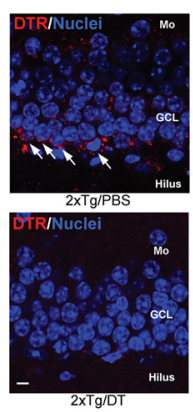

C

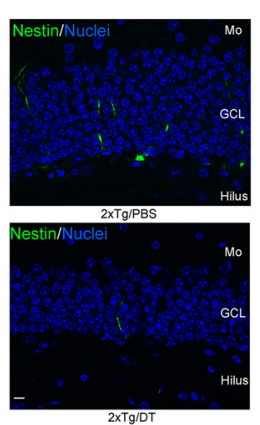

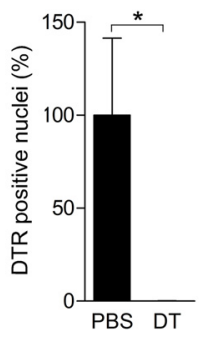
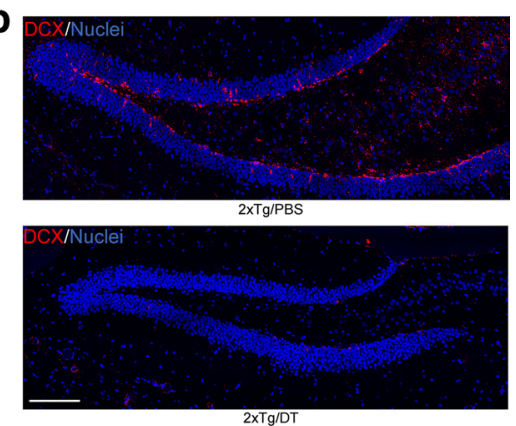

d

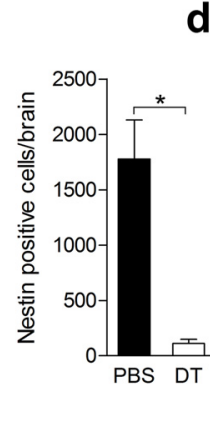

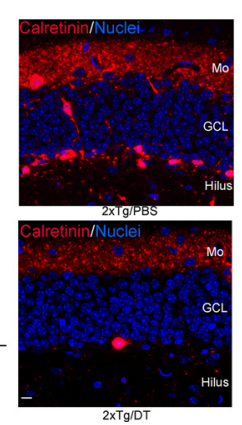

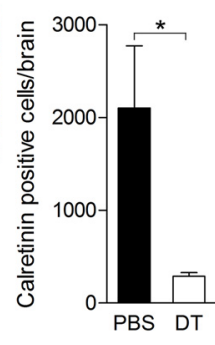

Figure 4. Ablating tagged neurons. $\boldsymbol{a}, \mathrm{DT}(n=4)$ but not PBS $(n=6)$ efficiently ablated DTR-expressing cells in the DG (scale bar, $10 \mu \mathrm{m}) \cdot \boldsymbol{b}-\boldsymbol{d}$, Consistent with this, DT treatment reduced overall numbers of doublecortin ${ }^{+}$(DCX; scale bar, $\left.150 \mu \mathrm{m}\right)(\boldsymbol{b})$, nestin $^{+}$(scale bar, $\left.10 \mu \mathrm{m}\right)(\boldsymbol{c})$, and calretinin ${ }^{+}$(scale bar, $\left.10 \mu \mathrm{m}\right)(\boldsymbol{d})$ cells in the DG of 2xTg mice. Mo, Molecular layer; GCL, granule cell layer. ${ }^{*} p<0.05$.

a CTR
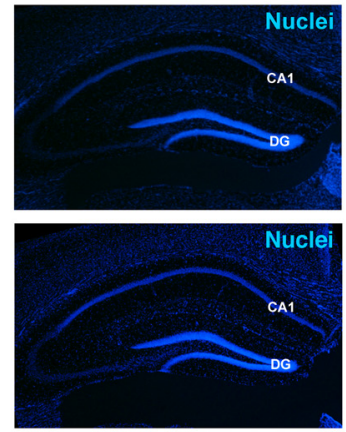

b

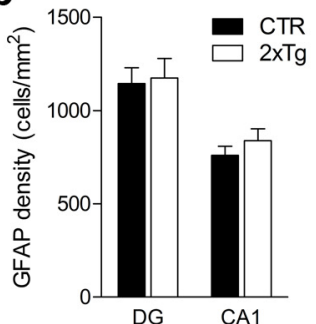

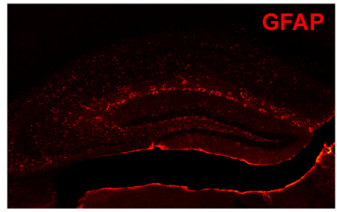

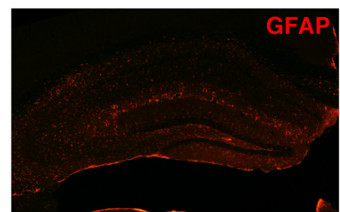

C

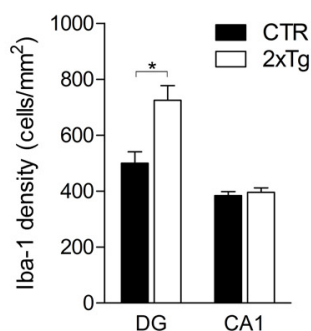

Figure 5. DT-induced ablation produces minimal inflammation. $\boldsymbol{a}$, GFAP (red) and ionized calcium binding adaptor molecule 1 (Iba1; green) expression in CTR $(n=5)$ and $2 x \operatorname{~Tg}(n=4)$ mice $24 \mathrm{~h}$ after administration of DT. $\boldsymbol{b}$, GFAP levels were similar for CTR and 2xTg mice in both the DG and CA1 regions. c, lba1 expression was increased in 2xTg mice only in the DG and not in the CA1 region. Note that Iba1 expression was mainly limited to the subgranular zone and innermost layer of the $D G$, a pattern that matches the distribution of tagged (i.e., DTR $^{+}$or LaCZ $^{+}$) cells after TAM treatment. ${ }^{*} p<0.05$.

tion (ANOVAs and unpaired $t$ tests; Genotype effects, $p>0.05$ ) (Fig. $6 b-j$ ). In subsequent behavioral experiments, $2 x T g$ and littermate control mice (either nestin-Cre ${ }^{\mathrm{ERT} 2+}$ or $\mathrm{iDTR}^{+}$but not both) were used. All mice were treated with TAM and subsequently treated with DT either before or after training. Impor-

tantly, this design ensures that group effects cannot be attributed to nonspecific effects of TAM or DT.

Posttraining ablation of tagged neurons degrades a contextual fear memory

We used our tag and ablate strategy to test whether deletion of adult-generated neurons after training would impair subsequent memory expression. To test memory, we first used a contextual fear conditioning task in which mice learn an association between a context and an aversive event (i.e., the delivery of a mild footshock). When returned to the same context, contextual fear memory is inferred from an increase in freezing behavior (Kim and Fanselow, 1992). The specificity of the memory may then be evaluated by comparing freezing levels in the trained versus alternate contexts (Wang et al., 2009). This task is hippocampus dependent (Kim and Fanselow, 1992) and engages dentate granule cells (including those generated during adulthood) (Stone et al., 2011). We trained $2 x T g$ and control mice with a tone-shock pairing 7 weeks after TAM treatment (Fig. 7a), a time point when the vast majority of tagged, adult-generated neurons have matured (i.e., $\sim 94 \%$ express the mature neuronal marker calbindin, indicating that they are $\sim 4$ weeks of age or older (Zhao et al., 2008). During training, both $2 \times \mathrm{Tg}$ and control mice responded similarly to the shock (unpaired $t$ test, $p>0.05$ ) (Fig. $7 b$ ) and exhibited equivalent levels of freezing immediately before and after the footshock (Genotype $\times$ Training phase ANOVA, effect of Training phase only, $F_{(1,20)}=31.85, p<$ 0.001 ; planned comparison for aftershock freezing indicated CTR vs $2 \times T g$, $p>0.05$ ) (Fig. 7c), indicating that tagging neurons (DTR expression) alone does not alter responsivity to shock or general activity levels. After DT treatment, control mice exhibited robust freezing in the trained context (context $\mathrm{A}$ ) and less freezing in an alternate context (context $B$ ) that shared a number of overlapping features with the training context. In contrast, $2 \mathrm{xTg}$ exhibited robust but equivalent levels of freezing in both (Genotype $\times$ Context ANOVA, Genotype $\times$ Context interaction, $F_{(1,21)}=17.66, p<0.005$; Newman-Keuls post hoc tests indicated $A_{\text {СTR }}>B_{\text {СTR }}$ only, $p<0.05$ ) (Fig. $7 d$ ), indicating that this posttraining ablation abolished the ability to discriminate two similar contexts (unpaired $t$ test, $t_{(21)}=4.27, p<0.001$ ) (Fig. $7 e$ ). To test whether this posttraining ablation abolished the ability to discriminate dissimilar contexts, we next placed mice in a third context (context C), which had no overlapping features with the original training 
a

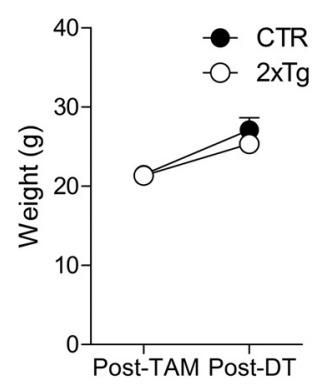

f

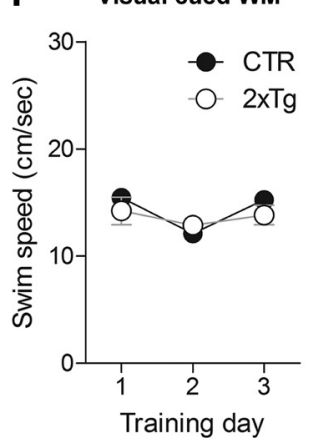

b

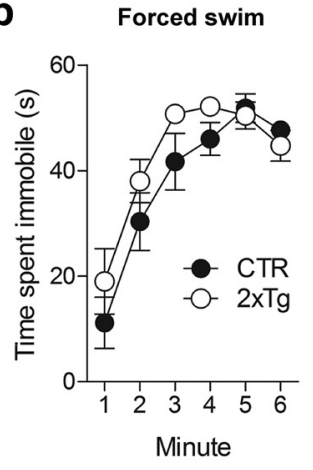

g

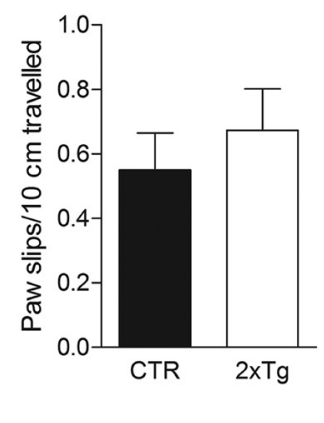

C

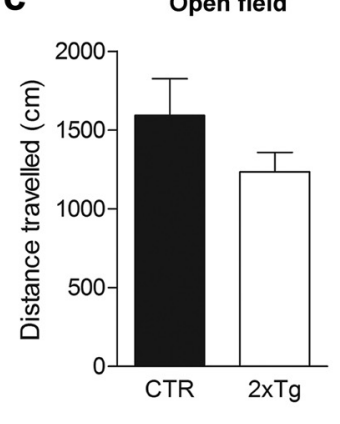

h

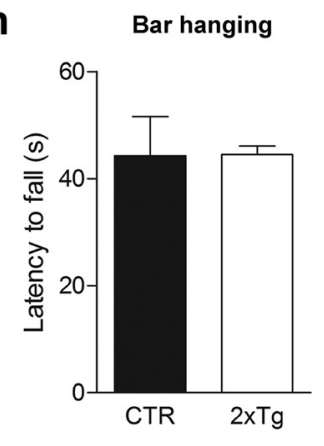

d

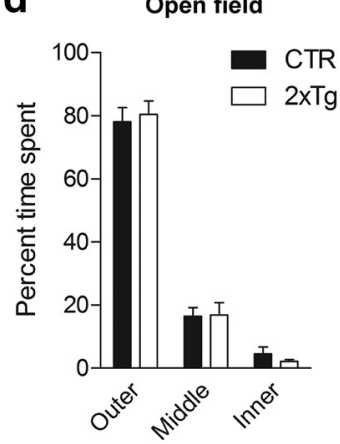

i

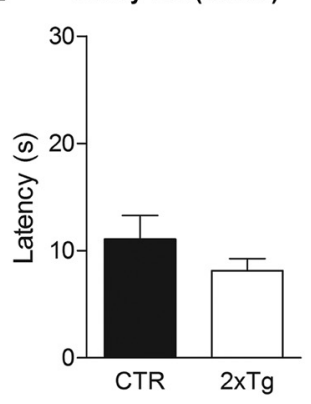

e

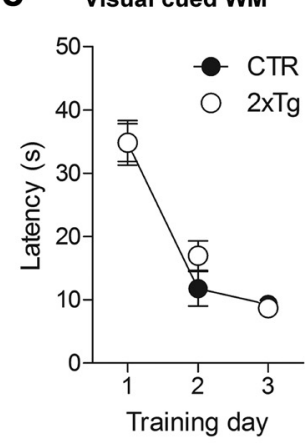

j

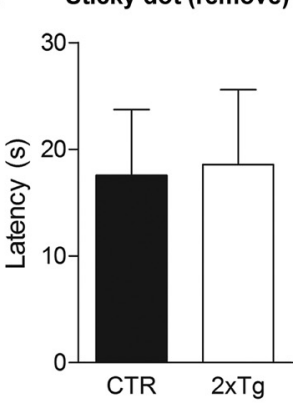

Figure 6. General health and behavior are not altered by DT-induced ablation. Seven weeks after the completion of TAM treatment, $\operatorname{CTR}(n=6)$ and $2 x \operatorname{Tg}(n=7)$ mice were treated with DT. $\boldsymbol{a}$, Body weights were not different after the completion of TAM or DT treatments. $\boldsymbol{b}-\boldsymbol{j}$, The behavior of TAM- and DT-treated (TR and $2 x T g$ mice was characterized in a battery of tests. We observed no effect on time spent immobile in the forced swim test $(\boldsymbol{b})$; total exploration in the open field (c); time spent in the outer, middle, and innermost regions of the open field $(\boldsymbol{d})$; latency to find platform in the visual discrimination water maze (WM) (e); swim speed during training in the visual discrimination water maze $(\boldsymbol{f})$; paw slips in the beam walk test $(\boldsymbol{g})$; latency to fall in the bar hanging test $(\boldsymbol{h})$; latency to detect adhesive tape in the sticky dot test $(\boldsymbol{i})$; or latency to remove adhesive tape in the sticky dot test $(\boldsymbol{j})$.

context. In context $\mathrm{C}$, both $2 \mathrm{xTg}$ and control mice exhibited similarly low levels of freezing (unpaired $t$ test, $p>0.05$ ) (Fig. $7 f$ ). Therefore, these results indicate that posttraining ablation of adult-generated neurons led to the degradation (but not the erasure) of a contextual fear memory: whereas recognition of the training context was unaffected, the ability to discriminate between similar (but not dissimilar) contexts was impaired.

The present experimental design rules out several alternative interpretations of the data. First, the absence of freezing in context $\mathrm{C}$ indicates that the discrimination deficit in $2 \mathrm{xTg}$ mice was not attributable to an overall increase in propensity to freeze. Second, because DT was administered in the home cage, memory degradation effects cannot be caused by blockade of a reactivation-induced phenomenon, such as reconsolidation $(\mathrm{Na}-$ der et al., 2000). Third, memory for the tone-shock association was unaltered after the posttraining ablation (unpaired $t$ test, $p>$ 0.05 ) (Fig. $7 g$ ). Because this type of memory is supported by the amygdala (Han et al., 2009), this suggests that deleting adultgenerated neurons affects hippocampus-dependent memory only. Consistent with this, in a separate group of mice, similar posttraining ablation did not affect expression of a previously acquired conditioned taste aversion memory (Group ANOVA, Group effect, $F_{(4,23)}=5.53, p<0.01$; Newman-Keuls post hoc tests indicated stronger saccharin preference in the CTR/SAL group compared with the CTR/LiCL and $2 \mathrm{xTg} / \mathrm{LiCl}$ groups, $p<$ 0.05) (Fig. 7h).

Pretraining ablation of tagged neurons does not prevent formation of new contextual fear memory

We next tested whether ablation of a similar population of adultgenerated neurons immediately before training would impair ac- quisition of a new contextual fear memory. As in the previous experiment, 2xTg and control mice were treated with TAM, trained 7 weeks later, and tested after a 1 week delay. In this case, however, DT was administered during the week before training rather than during the week after training (Fig. 8a). This experimental design ensures that DT targets an equivalent population of neurons (in terms of number and maturity) and that the retention delay is identical to the first experiment. During training, both $2 \mathrm{xTg}$ and control mice responded similarly to the shock (unpaired $t$ test, $p>0.05$ ) (Fig. $8 b$ ) and exhibited equivalent levels of freezing immediately before and after shock delivery (Genotype $\times$ Training phase ANOVA, effect of Training phase only, $F_{(1,25)}=40.95, p<0.0001$; planned comparison for aftershock freezing indicated CTR vs $2 x T g, p>0.05$ ) (Fig. $8 c$ ), indicating that the pretraining DT-induced ablation did not affect shock reactivity or general activity levels. One week after training, both $2 \mathrm{xTg}$ and control mice froze more in context A compared with context B (Genotype $\times$ Context ANOVA, effect of Context only, $F_{(1,25)}=9.41, p<0.005$; planned comparisons indicated $A_{\mathrm{CTR}}>B_{\mathrm{CTR}}$ and $A_{2 \mathrm{xTg}}>B_{2 \mathrm{xTg}}, p<0.05$ ) (Fig. $8 d$ ), and, furthermore, the degree of discrimination did not differ between groups (unpaired $t$ test, $p>0.05$ ) (Fig. 8e). As expected, both 2xTg and control mice exhibited similarly low levels of freezing in context $\mathrm{C}$ (unpaired $t$ test, $p>0.05$ ) (Fig. $8 f$ ), and tone freezing was also unaffected by pretraining ablation (unpaired $t$ test, $p>0.05$ ) (Fig. $8 g$ ).

In the first experiment, ablation of a population of predominantly mature, adult-generated neurons immediately after training impaired subsequent memory expression, presumably because these neurons had become an integral component of the memory trace. In contrast, deletion of an 


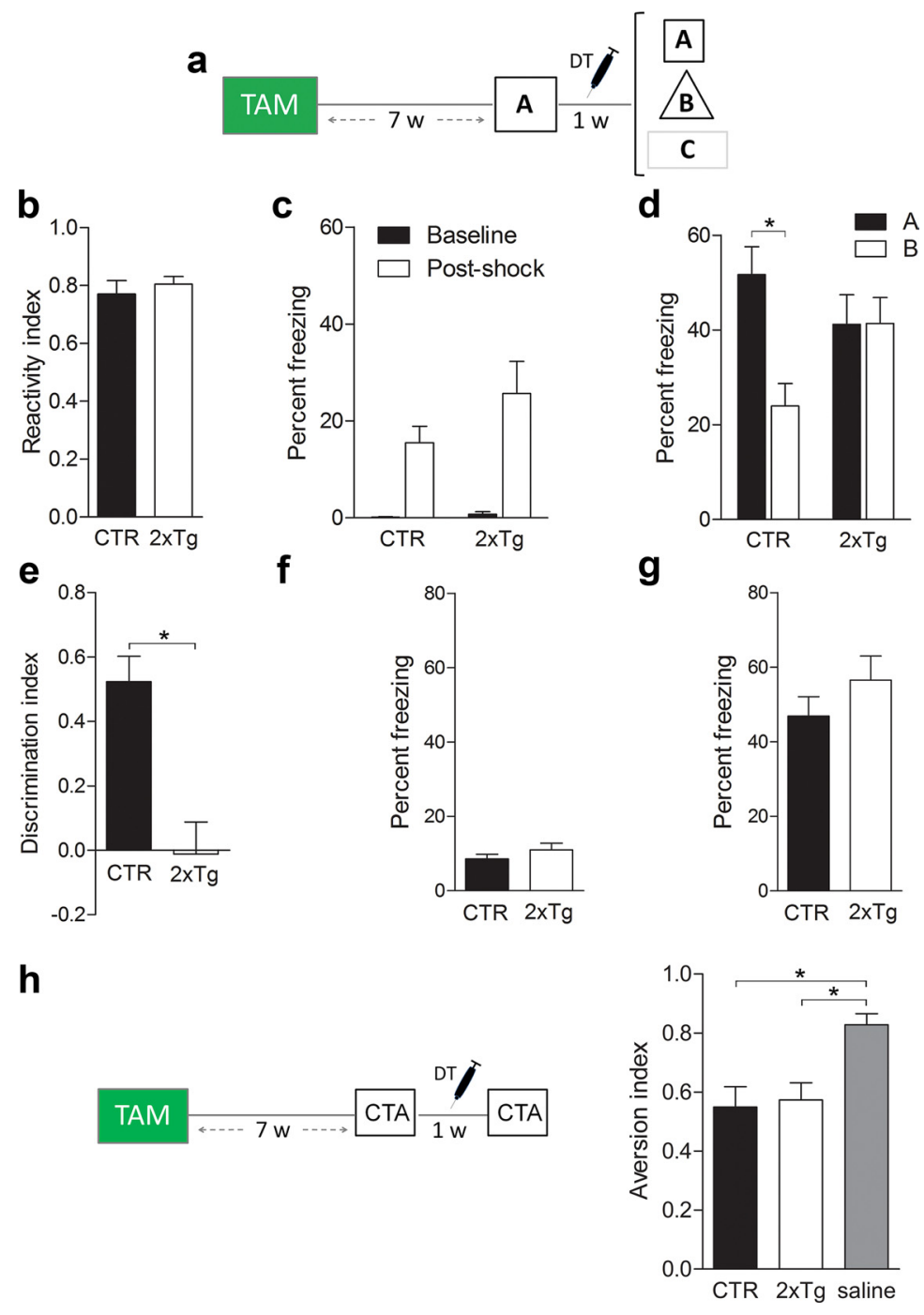

Figure 7. Posttraining ablation of adult-generated neurons degrades contextual fear memory. $\boldsymbol{a}$, Mice were treated with TAM and trained in context A. After DT-induced ablation of adult-generated neurons, contextual memory was assessed in contexts A-C. $\boldsymbol{b}, \boldsymbol{c}$, During training, $\operatorname{CTR}(n=12)$ and $2 x \operatorname{xg}(n=11)$ mice exhibited similar response to shock $(\boldsymbol{b})$ and freezing (c) levels before and after shock delivery. $\boldsymbol{d}$, After DT treatment, CTR mice froze more in the trained context (A) versus a similar context (B). In contrast, $2 x \operatorname{Tg}$ mice froze equally in both. $\boldsymbol{e}$, DT-induced ablation abolished context discrimination. $\boldsymbol{f}, \boldsymbol{g}$, Freezing in a dissimilar context $(C)(\boldsymbol{f})$ and tone fear $(\boldsymbol{g})$ were similar in CTR and 2xTg mice. $\boldsymbol{h}$, Mice were treated with TAM and trained in a conditioned taste aversion task. During training, saccharin was paired with $0.15 \mathrm{M} \mathrm{LiCl}$. After DT-induced ablation of adult-generated neurons, preference for saccharin versus water was evaluated. CTR $(n=12)$ and $2 x \operatorname{Tg}(n=11)$ mice exhibited equivalent preference for saccharin. Importantly, this preference was lower compared with mice $(n=11)$ for which saccharin was paired with saline (rather than LiCl) during training. ${ }^{*} p<0.05$.

equivalent population of neurons immediately before training did not prevent the formation of a new contextual fear memory, indicating that memory formation may be supported by existing dentate granule cells when this population of adultgenerated neurons is absent at the time of training. Moreover, the preserved ability to discriminate between both similar and dissimilar contexts suggests that pretraining removal of adult-generated neurons did not significantly impact memory quality.

\section{Posttraining ablation of tagged neurons degrades spatial memory}

The hippocampus is engaged by multiple forms of learning. To evaluate the generality of our findings, we next asked whether similar posttraining ablations would impact spatial memory. To address this, we used the hidden platform version of the water maze task, in which both acquisition and expression depend on the hippocampus (Riedel et al., 1999; Teixeira et al., 2006). As before, we trained $2 \mathrm{xTg}$ and control mice in the water maze 7 weeks after TAM treatment (Fig. 9a). During training, latency to find the platform declined similarly in both groups (Genotype $\times$ Training day ANOVA, effect of Training day only, $F_{(4,22)}=19.21$, $p<0.0001$ ), indicating that tagging (DTR expression) does not interfere with swimming, motivation, and vision required for acquisition of a spatial memory (Fig. $9 b$ ). After the completion of training, $2 x T g$ and control mice were administered DT, and their spatial memory was assessed in a probe test $7 \mathrm{~d}$ later. In this test, $2 \mathrm{xTg}$ mice searched less selectively than control mice, spending less time in the target zone (Genotype $\times$ Zone ANOVA, Genotype $\times$ Zone interaction, $F_{(1,22)}=5.67, p<0.05$; planned comparisons indicated $T_{\mathrm{CTR}}>$ $T_{2 \mathrm{xTg}}, T_{\mathrm{CTR}}>O_{\mathrm{CTR}}$, and $T_{2 \mathrm{xTg}}>O_{2 \mathrm{xTg}}$, $p<0.05$ ) (Fig. 9c). We additionally conducted a similar experiment in which TAM-treated 2xTg and control mice were trained in the water maze but were administered PBS rather than DT before the probe test (Fig. 9d). During training, latency to find the platform declined similarly in both groups (Training day $\times$ Genotype ANOVA, effect of Training day only, $F_{(4,23)}=22.93, p<0.0001$ ) (Fig. 9e), and in the probe test, both $2 x T g$ and control mice exhibited robust spatial memory (Genotype $\times$ Zone ANOVA, effect of Zone only, $F_{(1,22)}=38.50, p<0.0001$; planned comparisons indicated $T_{\mathrm{CTR}}>$ $O_{\mathrm{CTR}}$ and $T_{2 \mathrm{xTg}}>O_{2 \mathrm{xTg}}, p<0.05, T_{\mathrm{CTR}}$ vs $T_{2 \mathrm{xTg}}, p>0.05$ ) (Fig. $9 f$ ). Together, these findings indicate that neither DTR tagging (in the absence of DT) nor DT administration alone (in the absence of DTR tagging) impairs memory. Instead a combination of DTR tagging and DT is necessary to induce memory loss.

Consistent with our fear-conditioning data, these results indicate that selective removal of adult-generated neurons after training impairs subsequent memory expression. In contrast, DT-induced ablation of an equivalent population of adultgenerated neurons immediately before training had no effect on the formation of a new spatial memory (Fig. $9 g$ ). After DT treatment, both $2 x T g$ and CTR mice learned to find the platform with progressively shorter latencies (Genotype $\times$ Training day ANOVA, effect of Training day only, $F_{(4,23)}=9.48, p<0.01$ ) (Fig. 9 h). Likewise, in the probe test 1 week later, both $2 x T g$ and CTR mice searched selectively, spending equivalent amounts of time in the target zone (Genotype $\times$ Zone ANOVA, effect of Zone only, $F_{(1,23)}=8.14, p<0.01$; planned comparisons indicated $T_{\mathrm{CTR}}>O_{\mathrm{CTR}}, T_{2 \mathrm{xTg}}>O_{2 \mathrm{xTg}}, p<0.05, T_{\mathrm{CTR}}$ vs $T_{2 \mathrm{xTg}}, p>$ 0.05 ) (Fig. 9i). This suggests that new spatial learning may be 
supported by existing dentate granule cells when adult-generated neurons are not present at the time of training. Importantly, this pretraining ablation did not affect swimming, navigation, vision, or motivation required for acquisition and expression of spatial memory. Therefore, as pretraining and posttraining ablations targeted equivalent populations of adultgenerated neurons, these results exclude the possibility that such performance factors could account for spatial memory loss after posttraining ablations.

Posttraining ablation of tagged neurons degrades remote spatial memory

Expression of water maze memory depends on the hippocampus for at least 1 month after training (Clark et al., 2005; Teixeira et al., 2006). To address whether adult-generated neurons play a persistent role in memory expression, we next treated additional groups of control and 2xTg mice with DT 1 month (rather than $1 \mathrm{~d}$ ) after training (Fig. 9j). As before, both groups learned to locate the platform during training (Genotype $\times$ Training day ANOVA, effect of Training day only, $F_{(4,24)}=26.83, p<0.0001$ ) (Fig. $9 k$ ) and control mice exhibited robust spatial memory even when tested more than 1 month later. In contrast, at this remote time point, 2xTg mice searched less selectively compared to control mice, spending less time in the target zone (Genotype $\times$ Zone ANOVA, Genotype $\times$ Zone interaction, $F_{(1,24)}=3.53, p=$ 0.07; planned comparisons indicated that $T_{\mathrm{CTR}}>T_{2 \mathrm{xTg}}, T_{\mathrm{CTR}}>$ $O_{\text {CTR }}$, and $\mathrm{T}_{2 \mathrm{xTg}}>O_{2 \mathrm{xTg}}, p<0.05$ ) (Fig. 9l). These findings indicate that adult-generated neurons play an integral and enduring role in the expression of a spatial memory.

Posttraining ablation degrades visual discrimination memory Posttraining ablation of adult-generated neurons impaired the ability to discriminate between two similar contexts in the fearconditioning experiment. To further explore the nature of this deficit, we next developed a water maze visual discrimination task. In this task, two similar cues (one vertically striped, one horizontally striped) were positioned above the surface of the water. Across training trials, the locations of these two cues varied pseudorandomly. However, one of the cues was always located above a hidden platform (e.g., horizontal stripes). To evaluate whether this form of visual discrimination memory depends on the hippocampus, we first examined the impact of posttraining cytotoxic hippocampal lesions (Fig. 10a). During training, both groups of mice learned to discriminate between the reinforced and nonreinforced cues (Lesion $\times$ Training day ANOVA, effect of Training day only, $F_{(4,68)}=52.69, p<0.0001$ ) (Fig. 10b). Mice received lesion or sham surgery $1 \mathrm{~d}$ after training, and discrimination memory was subsequently assessed in a probe test in which both cues were present but neither reinforced. In this probe test, control mice spent significantly more time searching close to the previously reinforced cue than the nonreinforced cue in CTR and $2 x T g$ mice. ${ }^{*} p<0.05$.

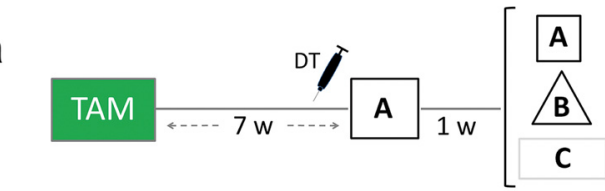

c
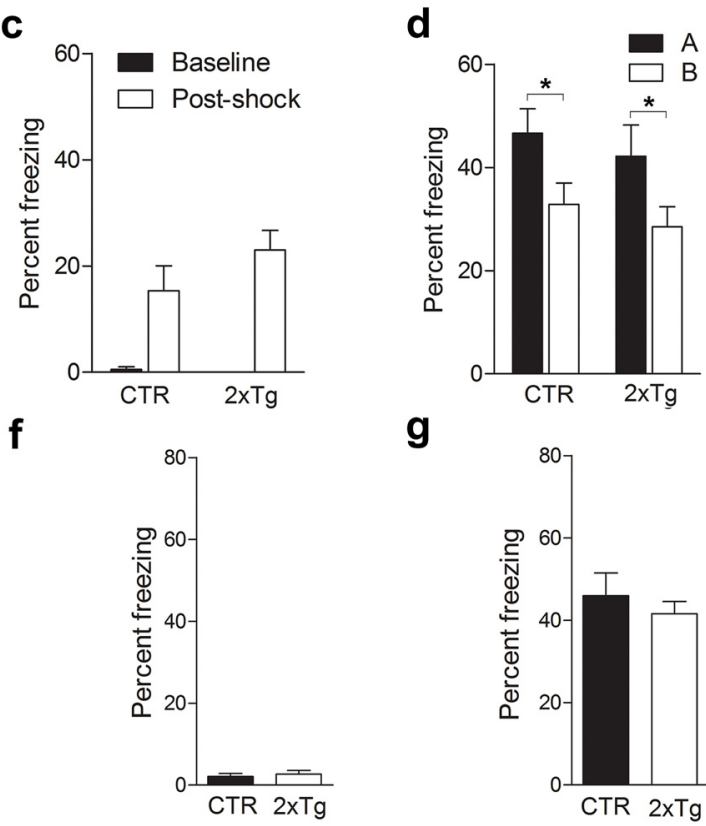

g

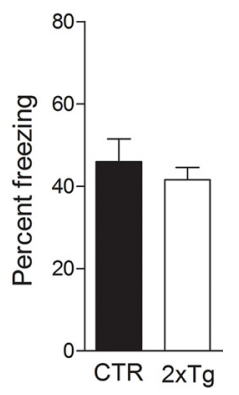

Figure 8. Pretraining ablation of adult-generated neurons does not prevent the formation of a new contextual fear memory. $\boldsymbol{a}$, $B(\boldsymbol{d})$, and the degree of discrimination did not differ $(\boldsymbol{e}) . \boldsymbol{f}, \boldsymbol{g}$, Freezing in a dissimilar context $(\boldsymbol{f})$ and tone fear $(\boldsymbol{g})$ were equivalent

(planned paired $t$ test, $t_{(8)}=4.27, p<0.05$ ). In contrast, mice with cytotoxic hippocampal lesions spent similarly little time close to either cue (planned paired $t$ test, $p>0.05$ ) (Fig. 10c). Our lesions affected $\sim 66 \pm 7 \%$ of hippocampal tissue (Fig. 10d). Similar hippocampal lesions in rats produce equivalent deficits (Clark et al., 2007) and indicate that an intact hippocampus is necessary for the expression of this form of visual discrimination memory.

We next evaluated whether posttraining ablation of adultgenerated neurons would similarly impair the expression of a visual discrimination memory (Fig. 10e). During training, 2xTg and control mice learned to discriminate between the reinforced and nonreinforced cues (Genotype $\times$ Training day ANOVA, effect of Training day only, $F_{(4,21)}=24.44, p<0.0001$ ) (Fig. 10f). After training, both groups of mice were administered DT, and discrimination memory was assessed in a probe test. As before, control mice spent more time searching close to the previously reinforced cue compared with the nonreinforced cue in the probe test (planned paired $t$ test, $t_{(11)}=3.02, p<0.01$ ). Interestingly, DT-induced ablation produced a more subtle deficit than cytotoxic hippocampal lesions. Although discrimination was abolished in the $2 \mathrm{xTg}$ mice (planned paired $t$ test, $p>0.05$ ), their propensity to search close to either of the cues remained intact (Fig. 10g,h). Therefore, these results indicate that posttraining ablation of a population of predominantly mature, adultgenerated neurons led to the degradation (rather than complete erasure) of a visual discrimination memory: some general features of the memory were retained (e.g., cue-platform associa- 
a

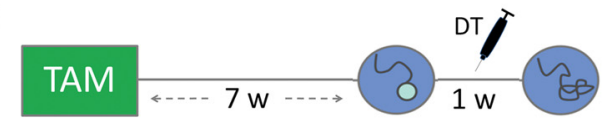

b

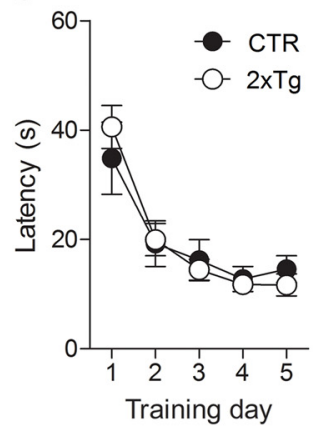

C

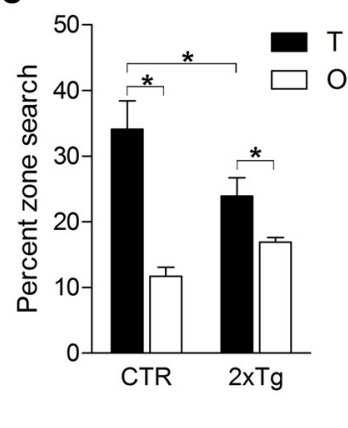

g

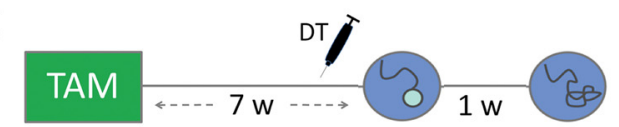

d

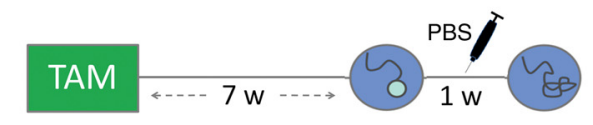

e

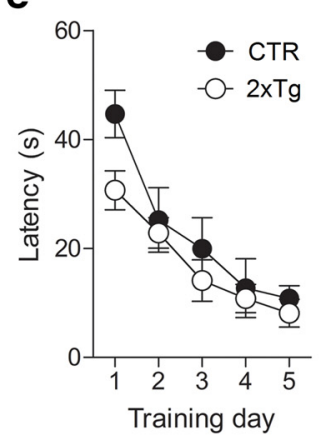

$\mathbf{f}$

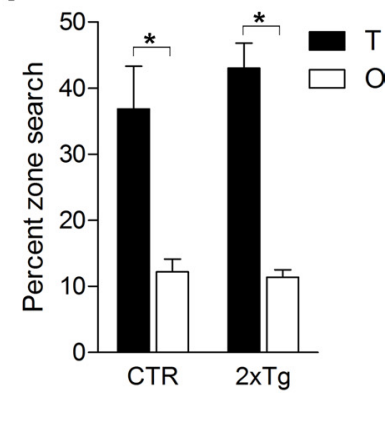

j

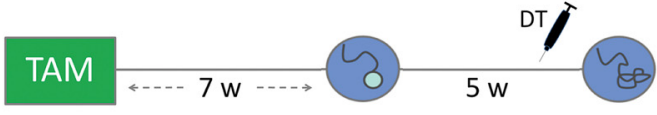

k

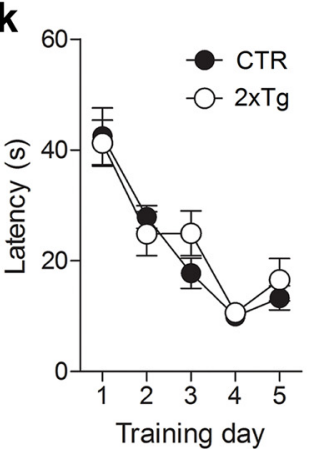

I

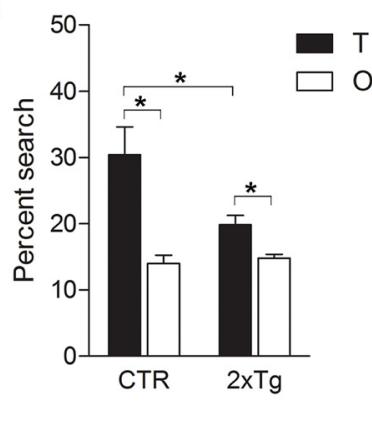

Figure 9. Posttraining (but not pretraining) ablation of adult-generated neurons impairs spatial memory expression. $\boldsymbol{a}$, Mice were treated with TAM and trained in the water maze. After DT-induced ablation of adult-generated neurons, spatial memory was assessed in a probe test. $\boldsymbol{b}$, During training, latency to find platform declined equivalently in CTR ( $n=12$ ) and 2xTg $(n=12)$ mice. c, After DT-induced ablation, 2xTg mice searched less selectively compared with CTR mice, spending less time in the target zone (T). $\boldsymbol{d}$, Additional groups of TAM-treated mice were trained in the water maze. However, mice were treated with PBS (rather than DT) during the week preceding memory testing. $\boldsymbol{e}$, During training, latency to find platform declined equivalently in CTR $(n=11)$ and $2 x \operatorname{Tg}(n=14)$ mice. $f$, In the probe test, both CTR and 2xTg mice searched selectively, spending more time in the target zone compared with other $(0)$ nontarget zones in the pool. $\boldsymbol{g}$, Mice were trained in the hidden version of the water maze after the completion of TAM treatment. During the week before training, mice were treated with DT. $\boldsymbol{h}$, During training, latency to find the platform declined equivalently in CTR $(n=14)$ and $2 x \operatorname{~g~}(n=11)$ mice. $\boldsymbol{i}$, In the probe test, both CTR and 2xTg mice searched selectively at the target zone. $j$, Mice were treated with TAM and trained in the water maze. One month later, mice were treated with DT, and spatial memory was assessed in a probe test. $\boldsymbol{k}$, During training, latency to find platform declined equivalently in CTR $(n=14)$ and $2 \times \operatorname{Tg}(n=12)$ mice. $I$, After DT-induced ablation at the remote time point, $2 \times \operatorname{Tg}$ searched less selectively compared with CTR mice, spending less time in the target zone. ${ }^{*} p<0.05$.

tion), but the ability to discriminate between similar cues was impaired.

\section{Discussion}

In these experiments, we used a tag and ablate transgenic strategy to examine the role of adult-generated neurons in hippocampal memory. This approach offered two key advantages. First, unlike previous approaches that targeted neural stem or progenitor cells to produce a global disruption of neurogenesis (Clelland et al., 2009; Deng et al., 2009; Dupret et al., 2008; Garthe et al., 2009; Imayoshi et al., 2008; Kitamura et al., 2009; Saxe et al., 2006; Shors et al., 2001; Zhang et al., 2008), our tag and ablate system allowed us to specifically target a population of adult-generated neurons that were predominantly born several weeks before training, without impacting ongoing proliferative activity in the adult hippocampus. Second, whereas previous approaches primarily manipulated neurogenesis before learning, our strategy allowed us control over the timing of the ablation. Therefore, using this system, we were able to ablate adult-generated neurons before or after memory formation. We found that selective ablation of adult-generated neurons immediately (or up to 1 month) after training impaired subsequent memory expression in three distinct hippocampus-dependent tasks. Previous studies provided correlative evidence that adult-generated neurons are activated during the formation and expression of hippocampal memories. The present findings, that their posttraining ablation disrupts expression of a previously acquired memory, provides direct experimental evidence that these neurons, if available at the time of learning, come to form an essential and enduring component of hippocampal memory traces.

To ablate populations of adult-generated granule cells in a temporally specific manner, we took advantage of the well characterized DT system (Buch et al., 2005). DT reliably induces apoptosis following receptor-mediated endocytosis (Dorland et al., 1979), but wild-type mouse cells are 10,000-fold less sensitive to 
a

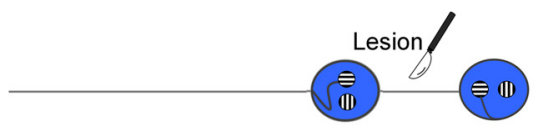

b

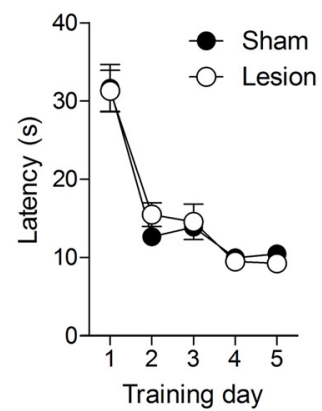

d

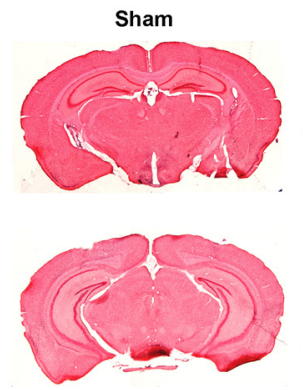

C
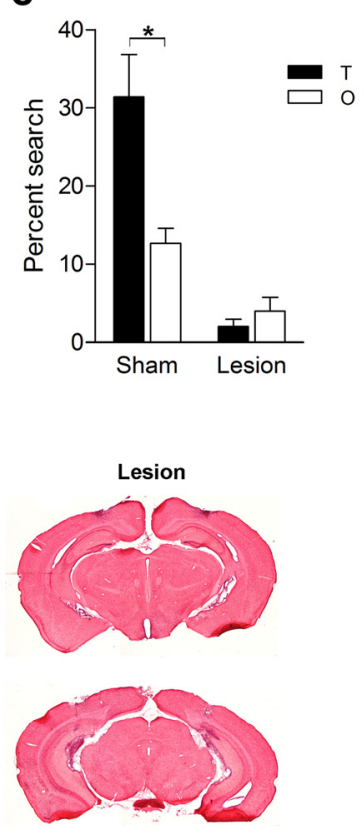

e

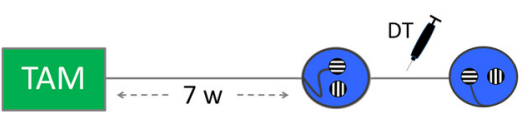

f

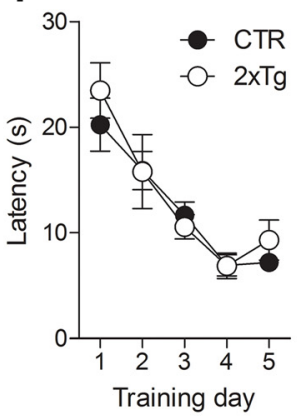

g

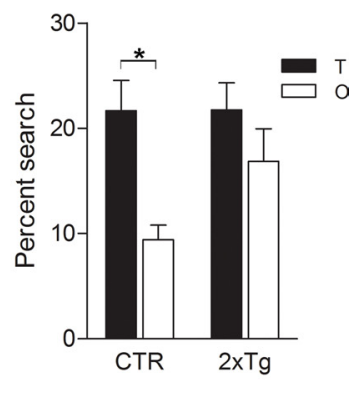

h

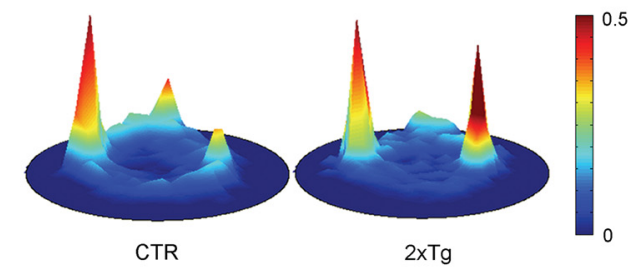

Figure 10. Posttraining ablation of adult-generated neurons impairs visual discrimination memory. $\boldsymbol{a}$, During training, a submerged platform was located beneath one of two visual cues (e.g., horizontal stripes). After training, the hippocampus was lesioned, and discrimination between the reinforced and nonreinforced cues was evaluated in a probe test. $\boldsymbol{b}$, Before surgery, latency to locate the platform declined at similar rates in lesion $(n=10)$ and sham $(n=9)$ mice. $c$, After surgery, whereas sham mice searched selectively at the reinforced cue, lesion mice did not search at either cue. $\boldsymbol{d}$, Representative images of brains from sham and lesion mice. $\boldsymbol{e}$, CTR $(n=12)$ and $2 \times \operatorname{Tg}(n=11)$ mice were treated with TAM and trained in the visual discrimination task. After DT-induced ablation of adult-generated neurons, visual discrimination memory was assessed in a probe test. $f$, Across training days, latency to locate the platform declined at similar rates in CTR and 2xTg mice. $\boldsymbol{g}$, In the probe test, whereas (TR mice searched selectively at the reinforced cue, $2 x \operatorname{Tg}$ mice spent equivalent amounts of time close to the reinforced and nonreinforced cues. $\boldsymbol{h}$, Heat maps reflect preferential searching close to previously reinforced (left peak) versus nonreinforced (right peak) cue in CTR but not $2 x T g$ mice. Note that the peak at top of pool corresponds to the release point at the start of the probe test. ${ }^{*} p<0.05$.

DT than human or monkey cells (Eidels et al., 1983; Middlebrook and Dorland, 1977; Stenmark et al., 1988). We exploited the insensitivity of mouse cells to DT by using a transgenic line of mice in which a functional simian DTR receptor is expressed in a Crerecombinase-inducible fashion (iDTR mice). Crossing iDTR mice with mice that express an inducible Cre-recombinase in nestin ${ }^{+}$cells allowed us to permanently express DTRs in neural progenitor cells and their progeny. Importantly, we found that neither DT administration nor DTR expression alone affected memory, consistent with previous findings (Han et al., 2009). Rather, only the combination of DTR tagging and DT administration induced retrograde memory loss, showing the specificity of the system.

The cells targeted for ablation included progenitor cells, immature neurons, and mature neurons. Therefore, our posttraining ablation effects on memory might be caused by loss of any (or all) of these different cell populations. Indeed, genetic deletion of predominantly immature, adult-generated neurons is associated with long-term retention deficits in a water maze task (Deng et al., 2009), suggesting that this population of cells contributes to memory robustness. However, cellular imaging approaches suggest that adult-generated neurons are not maximally activated during memory formation and/or expression until they reach a more mature stage [ $>4$ weeks of age (Kee et al., 2007; Stone et al., 2011)]. In our experiments, the majority of tagged cells were mature (e.g., $94 \%$ were calbindin ${ }^{+}$and therefore $>4$ weeks of age
(Zhao et al., 2008)), and therefore it is very likely that loss of this population of mature, adult-generated neurons contributed significantly to memory loss.

In contrast to the impairment produced by posttraining ablation of adult-generated neurons, similar pre training ablation did not prevent the formation of new memories. These effects parallel those of partial hippocampal lesions in water maze [both hidden (Moser and Moser, 1998) and visual discrimination (Epp et al., 2008) versions] and contextual fear tasks (Frankland et al., 1998; Maren et al., 1997; Wiltgen et al., 2006). For example, whereas chemical lesions ablating $\sim 30 \%$ of hippocampal tissue disrupt the expression of a previously acquired water maze memory, similar-sized lesions do not prevent the acquisition of a new water maze memory (Moser and Moser, 1998). This suggests that, whereas spatial memories may normally be distributed throughout the hippocampus, new learning may be supported by residual tissue when the lesion precedes training. Analogously, here we show that in the absence of a large population of adultgenerated neurons, memory formation may be supported by existing dentate neurons without an obvious impact on memory quality. This potential for compensation by existing, developmentally generated granule cells may account for variable impact of pretraining disruptions of adult neurogenesis on memory formation. Although memory formation may be impaired by pretraining suppression of adult neurogenesis (Clelland et al., 2009; Deng et al., 2009; Drew et al., 2010; Dupret et al., 2008; Garthe et 
al., 2009; Imayoshi et al., 2008; Saxe et al., 2006; Shors et al., 2001; Tronel et al., 2010; Zhang et al., 2008), sometimes the effects of these types of manipulations are mild or even nonexistent (Deng et al., 2010; Hernandez-Rabaza et al., 2009; Jaholkowski et al., 2009). Many factors differ across studies and likely contribute to the discrepant results. The advantage of the current approach is that we were able to directly contrast pretraining and posttraining ablations under identical conditions (i.e., method of ablation, number and type of cells targeted, training paradigm, apparatus, etc.). Our finding that posttraining lesions had greater impact than pretraining lesions is consistent with the idea that targeting neurons after memory formation is likely more disruptive because these neurons have already become committed to the memory trace.

Because cell death is induced by apoptosis, rather than necrosis, using our DT system, impact on surrounding cells is minimized. Indeed, after DT-induced ablation, there was no hippocampus-wide increase in astrocyte number, and the increase in microglia number was restricted to the DG. Nonetheless, our ablation affected a large number of cells $(>30,000)$ and therefore might nonspecifically impact hippocampal function. However, the dissociable effects of pretraining and posttraining ablation on memory suggest that such off-target effects cannot account for the results. For example, the absence of pretraining effects in our water maze experiment indicates that DT-induced ablation did not simply affect swimming, navigation, vision, or motivation necessary for the expression of a spatial memory. Likewise, in our contextual fear experiment, the absence of pretraining effects indicates that DT-induced ablation did not simply affect the ability to perceive differences between similar contexts. Finally, it is worth noting that our DT-induced ablation should, in addition, lead to loss of subventricular zone-generated cells in the olfactory bulb. However, it is unlikely that the loss of these neurons can account for our retrograde memory effects since we observed consistent memory loss in three different tasks, each with different stimulus properties and performance demands. In particular, the two water maze-based tasks do not depend on olfactory information (Morris et al., 1982).

Neurogenesis in the DG can be classified into three broad periods: embryonic, postnatal, and adult. Embryonic and postnatal neurogenesis occurs as a result of proliferation in the primary, secondary, and tertiary dentate matrices. However, these germinal regions decline by postnatal day 10 . By postnatal days 20-30, and continuing throughout adulthood, neurogenesis becomes restricted to the subgranular zone (Altman and Bayer, 1990). Therefore, in our experiments we initiated TAM treatment in mice at 4 weeks of age [for similar experimental strategies, see Ables et al. (2010) and Sierra et al. (2010)]. Because proliferation rates are higher in this postjuvenile period, this approach enabled us to tag large numbers of granule cells. Even so this tagged population (including both cells generated during a post-juvenile period as well as during adulthood) represents no more than $6 \%$ of the entire population of granule cells at the time of ablation. That deletion of this relatively small proportion of dentate neurons was sufficient to produce robust retrograde memory deficits across three different tasks is perhaps surprising and suggests that this population of subgranular zone-generated neurons plays an especially important role within a broader network of dentate neurons supporting contextual fear, water maze and visual discrimination memories. Indeed, it is necessary to lesion $>15 \%$ of the entire hippocampus to produce similar ret- rograde memory deficits in the water maze (Moser and Moser, 1998). Since cells generated at different stages of development and adulthood seem to be integrated into hippocampal memory circuits at similar rates (Stone et al., 2011), this suggests that this population of subgranular zone-derived neurons may disproportionately influence hippocampal memory function and raises the possibility that granule cells derived from the subgranular zone may make distinct contributions to hippocampal memory relative to those generated in the primary, secondary, and tertiary matrices earlier on during development. What is the nature of this role? In the fear conditioning and visual discrimination tasks, posttraining ablation led to memory degradation rather than erasure. In both tasks, although some general features of the memory were retained (e.g., context-shock, cue-platform associations), the ability to discriminate between similar contexts and patterns was impaired. Consistent with recent reports (Clelland et al., 2009; Sahay et al., 2011), these deficits may suggest a specialized role for adult-generated neurons in disambiguating similar (but nonetheless discrete) representations (or pattern separation).

\section{References}

Ables JL, Decarolis NA, Johnson MA, Rivera PD, Gao Z, Cooper DC, Radtke F, Hsieh J, Eisch AJ (2010) Notch1 is required for maintenance of the reservoir of adult hippocampal stem cells. J Neurosci 30:10484-10492.

Altman J, Bayer SA (1990) Migration and distribution of two populations of hippocampal granule cell precursors during the perinatal and postnatal periods. J Comp Neurol 301:365-381.

Archer J (1973) Tests for emotionality in rats and mice: a review. Anim Behav 21:205-235.

Buch T, Heppner FL, Tertilt C, Heinen TJ, Kremer M, Wunderlich FT, Jung S, Waisman A (2005) A Cre-inducible diphtheria toxin receptor mediates cell lineage ablation after toxin administration. Nat Methods 2:419-426.

Chen GH, Wang YJ, Zhang LQ, Zhou JN (2004) Age- and sex-related disturbance in a battery of sensorimotor and cognitive tasks in Kunming mice. Physiol Behav 83:531-541.

Clark RE, Broadbent NJ, Squire LR (2005) Hippocampus and remote spatial memory in rats. Hippocampus 15:260-272.

Clark RE, Broadbent NJ, Squire LR (2007) The hippocampus and spatial memory: findings with a novel modification of the water maze. J Neurosci 27:6647-6654.

Clelland CD, Choi M, Romberg C, Clemenson GD Jr, Fragniere A, Tyers P, Jessberger S, Saksida LM, Barker RA, Gage FH, Bussey TJ (2009) A functional role for adult hippocampal neurogenesis in spatial pattern separation. Science 325:210-213.

Corvelo A, Eyras E (2008) Exon creation and establishment in human genes. Genome Biol 9:R141.

Deng W, Saxe MD, Gallina IS, Gage FH (2009) Adult-born hippocampal dentate granule cells undergoing maturation modulate learning and memory in the brain. J Neurosci 29:13532-13542.

Deng W, Aimone JB, Gage FH (2010) New neurons and new memories: how does adult hippocampal neurogenesis affect learning and memory? Nat Rev Neurosci 11:339-350.

Ding HK, Teixeira CM, Frankland PW (2008) Inactivation of the anterior cingulate cortex blocks expression of remote, but not recent, conditioned taste aversion memory. Learn Mem 15:290-293.

Dorland RB, Middlebrook JL, Leppla SH (1979) Receptor-mediated internalization and degradation of diphtheria toxin by monkey kidney cells. J Biol Chem 254:11337-11342.

Drew MR, Denny CA, Hen R (2010) Arrest of adult hippocampal neurogenesis in mice impairs single- but not multiple-trial contextual fear conditioning. Behav Neurosci 124:446-454.

Dupret D, Revest JM, Koehl M, Ichas F, De Giorgi F, Costet P, Abrous DN, Piazza PV (2008) Spatial relational memory requires hippocampal adult neurogenesis. PLoS One 3:e1959. 
Eidels L, Proia RL, Hart DA (1983) Membrane receptors for bacterial toxins. Microbiol Rev 47:596-620.

Epp J, Keith JR, Spanswick SC, Stone JC, Prusky GT, Sutherland RJ (2008) Retrograde amnesia for visual memories after hippocampal damage in rats. Learn Mem 15:214-221.

Forni PE, Scuoppo C, Imayoshi I, Taulli R, Dastru W, Sala V, Betz UA, Muzzi P, Martinuzzi D, Vercelli AE, Kageyama R, Ponzetto C (2006) High levels of Cre expression in neuronal progenitors cause defects in brain development leading to microencephaly and hydrocephaly. J Neurosci 26:9593-9602.

Frankland PW, Cestari V, Filipkowski RK, McDonald RJ, Silva AJ (1998) The dorsal hippocampus is essential for context discrimination but not for contextual conditioning. Behav Neurosci 112:863-874.

Garthe A, Behr J, Kempermann G (2009) Adult-generated hippocampal neurons allow the flexible use of spatially precise learning strategies. PLoS One 4:e5464.

Gropp E, Shanabrough M, Borok E, Xu AW, Janoschek R, Buch T, Plum L, Balthasar N, Hampel B, Waisman A, Barsh GS, Horvath TL, Bruning JC (2005) Agouti-related peptide-expressing neurons are mandatory for feeding. Nat Neurosci 8:1289-1291.

Gundersen HJ, Jensen EB, Kieu K, Nielsen J (1999) The efficiency of systematic sampling in stereology—reconsidered. J Microsc 193:199-211.

Han JH, Kushner SA, Yiu AP, Hsiang HL, Buch T, Waisman A, Bontempi B, Neve RL, Frankland PW, Josselyn SA (2009) Selective erasure of a fear memory. Science 323:1492-1496.

Hernandez-Rabaza V, Llorens-Martin M, Velazquez-Sanchez C, Ferragud A, Arcusa A, Gumus HG, Gomez-Pinedo U, Perez-Villalba A, Rosello J, Trejo JL, Hernandez-Rabaza V, Llorens-Martin M (2009) Inhibition of adult hippocampal neurogenesis disrupts contextual learning but spares spatial working memory, long-term conditional rule retention and spatial reversal. Neuroscience 159:59-68.

Imayoshi I, Sakamoto M, Ohtsuka T, Takao K, Miyakawa T, Yamaguchi M, Mori K, Ikeda T, Itohara S, Kageyama R (2008) Roles of continuous neurogenesis in the structural and functional integrity of the adult forebrain. Nat Neurosci 11:1153-1161.

Jaholkowski P, Kiryk A, Jedynak P, Ben Abdallah NM, Knapska E, Kowalczyk A, Piechal A, Blecharz-Klin K, Figiel I, Lioudyno V, Widy-Tyszkiewicz E, Wilczynski GM, Lipp HP, Kaczmarek L, Filipkowski RK (2009) New hippocampal neurons are not obligatory for memory formation; cyclin D2 knockout mice with no adult brain neurogenesis show learning. Learn Mem 16:439-451.

Jonasson Z (2005) Meta-analysis of sex differences in rodent models of learning and memory: a review of behavioral and biological data. Neurosci Biobehav Rev 28:811-825.

Kee N, Sivalingam S, Boonstra R, Wojtowicz JM (2002) The utility of Ki-67 and BrdU as proliferative markers of adult neurogenesis. J Neurosci Methods 115:97-105.

Kee N, Teixeira CM, Wang AH, Frankland PW (2007) Preferential incorporation of adult-generated granule cells into spatial memory networks in the dentate gyrus. Nat Neurosci 10:355-362.

Kempermann G, Jessberger S, Steiner B, Kronenberg G (2004) Milestones of neuronal development in the adult hippocampus. Trends Neurosci $27: 447-452$

Kim JJ, Fanselow MS (1992) Modality-specific retrograde amnesia of fear. Science 256:675-677.

Kitamura T, Saitoh Y, Takashima N, Murayama A, Niibori Y, Ageta H, Sekiguchi M, Sugiyama H, Inokuchi K (2009) Adult neurogenesis modulates the hippocampus-dependent period of associative fear memory. Cell 139:814-827.

Lagace DC, Whitman MC, Noonan MA, Ables JL, DeCarolis NA, Arguello AA, Donovan MH, Fischer SJ, Farnbauch LA, Beech RD, DiLeone RJ, Greer CA, Mandyam CD, Eisch AJ (2007) Dynamic contribution of nestin-expressing stem cells to adult neurogenesis. J Neurosci 27:12623-12629.

Maren S, Aharonov G, Fanselow MS (1997) Neurotoxic lesions of the dorsal hippocampus and Pavlovian fear conditioning in rats. Behav Brain Res 88:261-274.

McHugh TJ, Jones MW, Quinn JJ, Balthasar N, Coppari R, Elmquist JK, Lowell BB, Fanselow MS, Wilson MA, Tonegawa S (2007) Dentate gyrus NMDA receptors mediate rapid pattern separation in the hippocampal network. Science 317:94-99.

Middlebrook JL, Dorland RB (1977) Response of cultured mammalian cells to the exotoxins of Pseudomonas aeruginosa and Corynebacterium diphtheriae: differential cytotoxicity. Can J Microbiol 23:183-189.

Morris RG, Garrud P, Rawlins JN, O’Keefe J (1982) Place navigation impaired in rats with hippocampal lesions. Nature 297:681-683.

Moser E, Moser MB, Andersen P (1993) Spatial learning impairment parallels the magnitude of dorsal hippocampal lesions, but is hardly present following ventral lesions. J Neurosci 13:3916-3925.

Moser MB, Moser EI (1998) Distributed encoding and retrieval of spatial memory in the hippocampus. J Neurosci 18:7535-7542.

Nader K, Schafe GE, Le Doux JE (2000) Fear memories require protein synthesis in the amygdala for reconsolidation after retrieval. Nature 406:722-726.

Porsolt RD (1979) Animal model of depression. Biomedicine 30:139-140.

Riedel G, Micheau J, Lam AG, Roloff EL, Martin SJ, Bridge H, de Hoz L, Poeschel B, McCulloch J, Morris RG (1999) Reversible neural inactivation reveals hippocampal participation in several memory processes. Nat Neurosci 2:898-905.

Sahay A, Scobie KN, Hill AS, O'Carroll CM, Kheirbek MA, Burghardt NS, Fenton AA, Dranovsky A, Hen R (2011) Increasing adult hippocampal neurogenesis is sufficient to improve pattern separation. Nature 472:466-470

Saito M, Iwawaki T, Taya C, Yonekawa H, Noda M, Inui Y, Mekada E, Kimata Y, Tsuru A, Kohno K (2001) Diphtheria toxin receptor-mediated conditional and targeted cell ablation in transgenic mice. Nat Biotechnol 19:746-750.

Saxe MD, Battaglia F, Wang JW, Malleret G, David DJ, Monckton JE, Garcia AD, Sofroniew MV, Kandel ER, Santarelli L, Hen R, Drew MR (2006) Ablation of hippocampal neurogenesis impairs contextual fear conditioning and synaptic plasticity in the dentate gyrus. Proc Natl Acad Sci U S A 103:17501-17506.

Schallert T, Fleming SM, Leasure JL, Tillerson JL, Bland ST (2000) CNS plasticity and assessment of forelimb sensorimotor outcome in unilateral rat models of stroke, cortical ablation, parkinsonism and spinal cord injury. Neuropharmacology 39:777-787.

Shors TJ, Miesegaes G, Beylin A, Zhao M, Rydel T, Gould E (2001) Neurogenesis in the adult is involved in the formation of trace memories. Nature 410:372-376.

Sierra A, Encinas JM, Deudero JJ, Chancey JH, Enikolopov G, OverstreetWadiche LS, Tsirka SE, Maletic-Savatic M (2010) Microglia shape adult hippocampal neurogenesis through apoptosis-coupled phagocytosis. Cell Stem Cell 7:483-495.

Stenmark H, Olsnes S, Sandvig K (1988) Requirement of specific receptors for efficient translocation of diphtheria toxin A fragment across the plasma membrane. J Biol Chem 263:13449-13455.

Stone SSD, Teixeira CM, Zaslavsky K, Wheeler AL, Martinez-Canabal A, Wang AH, Sakaguchi M, Lozano AM, and Frankland PW (2011) Functional convergence of developmentally- and adult-generated granule cells in dentate gyrus circuits supporting hippocampus-dependent memory. Hippocampus Advance online publication. Retrieved September 7, 2010. doi:10.1002/hipo.20845.

Sutherland RJ, Weisend MP, Mumby D, Astur RS, Hanlon FM, Koerner A, Thomas MJ, Wu Y, Moses SN, Cole C, Hamilton DA, Hoesing JM (2001) Retrograde amnesia after hippocampal damage: recent vs. remote memories in two tasks. Hippocampus 11:27-42.

Tashiro A, Makino H, Gage FH (2007) Experience-specific functional modification of the dentate gyrus through adult neurogenesis: a critical period during an immature stage. J Neurosci 27:3252-3259.

Teixeira CM, Pomedli SR, Maei HR, Kee N, Frankland PW (2006) Involvement of the anterior cingulate cortex in the expression of remote spatial memory. J Neurosci 26:7555-7564.

Toni N, Teng EM, Bushong EA, Aimone JB, Zhao C, Consiglio A, van Praag H, Martone ME, Ellisman MH, Gage FH (2007) Synapse formation on neurons born in the adult hippocampus. Nat Neurosci 10:727-734.

Toni N, Laplagne DA, Zhao C, Lombardi G, Ribak CE, Gage FH, Schinder AF (2008) Neurons born in the adult dentate gyrus form functional synapses with target cells. Nat Neurosci 11:901-907.

Tronel S, Belnoue L, Grosjean N, Revest JM, Piazza PV, Koehl M, Abrous DN (2010) Adult-born neurons are necessary for extended contextual discrimination. Hippocampus. Advance online publication. Retrieved November 3, 2010. doi:10.1002/hipo.20895.

Trouche S, Bontempi B, Roullet P, Rampon C (2009) Recruitment of adultgenerated neurons into functional hippocampal networks contributes to 
updating and strengthening of spatial memory. Proc Natl Acad Sci U S A 106:5919-5924.

Wang SH, Teixeira CM, Wheeler AL, Frankland PW (2009) The precision of remote context memories does not require the hippocampus. Nat Neurosci 12:253-255.

Wiltgen BJ, Sanders MJ, Anagnostaras SG, Sage JR, Fanselow MS (2006) Context fear learning in the absence of the hippocampus. J Neurosci 26:5484-5491.

Wrobel CJ, Wright DC, Dedrick RL, Youle RJ (1990) Diphtheria toxin effects on brain-tumor xenografts. Implications for protein-based braintumor chemotherapy. J Neurosurg 72:946-950.

Zambrowicz BP, Imamoto A, Fiering S, Herzenberg LA, Kerr WG, Soriano P
(1997) Disruption of overlapping transcripts in the ROSA beta geo 26 gene trap strain leads to widespread expression of beta-galactosidase in mouse embryos and hematopoietic cells. Proc Natl Acad Sci U S A 94:3789-3794.

Zhang CL, Zou Y, He W, Gage FH, Evans RM (2008) A role for adult TLXpositive neural stem cells in learning and behaviour. Nature 451:10041007.

Zhao C, Teng EM, Summers RG Jr, Ming GL, Gage FH (2006) Distinct morphological stages of dentate granule neuron maturation in the adult mouse hippocampus. J Neurosci 26:3-11.

Zhao C, Deng W, Gage FH (2008) Mechanisms and functional implications of adult neurogenesis. Cell 132:645-660. 